PALABRAS CLAVE

Globalización

Sindicalismo

Desarrollo económico

Comercio internacional

Empleo

Distribución del ingreso

Países en desarrollo
Joseph Ramos

Profesor de la Facultad de Economía y

Negocios, Universidad de Chile

œjramos@econ.uchile.cl
REVISTA CEPAL 100 - ABRIL 2010

\section{Sindicalismo en el "Sur" en la era de la globalización}

\author{
Joseph Ramos
}

A en los países en desarrollo (el "Sur"). Se concluye, primero, que la globalización ha sido asimétrica: mucho más intensa en el comercio de bienes que en flujos de capital; débil en transferencia tecnológica y escasa en flujos migratorios. Segundo, se examinan el papel y la repercusión económica de los sindicatos. Se constata que, en contradicción con la ortodoxia, estos tienen escasa incidencia negativa en el empleo, pero reducen significativamente las desigualdades salariales. En vista del viraje registrado en el Sur a partir de los años ochenta — de estrategias de desarrollo basadas en la sustitución de importaciones para el mercado interno a estrategias orientadas a la exportación-, en la última sección se proponen nuevos desempeños y énfasis para el sindicalismo, más consistentes con esta reorientación estratégica, tanto a nivel nacional e internacional como dentro de la propia empresa. 


\section{I}

\section{Introducción}

Es probable que el sindicalismo, como es concebido tradicionalmente, haya llegado a su apogeo como fuerza mayor en la economía poco después de la Segunda Guerra Mundial. En ese entonces incluía a una buena parte de la fuerza de trabajo, ostentaba una potente capacidad negociadora y era un agente de gran influencia en la política nacional. Por distintas razones su poder comenzó a declinar. Su influencia puede estar aún más en jaque en el mundo actual, caracterizado por la "globalización", donde el eje de las decisiones económicas pasa cada vez más de la esfera nacional a la internacional.

En este artículo se pretende examinar las implicancias de la globalización para el sindicalismo, muy en particular para el sindicalismo de los países del Tercer Mundo (el "Sur"). ¿Qué amenazas se avecinan? ¿Qué oportunidades, si es que las hay, se presentan? ¿Qué ajustes requerirá el sindicalismo en su desempeño si se propone seguir siendo un actor relevante en el plano nacional e internacional?

En el artículo no se cuestionará la bondad o maldad de la globalización, sino que se partirá del hecho de que esta, en su forma gruesa, vino para quedarse e, incluso, ahondarse. Se considerará más bien cómo el sindicalismo puede modificar esas tendencias de la globalización más cuestionables para sus intereses, o cómo acelerar aquellas que potencialmente le son más favorables. En efecto, se considera que el sindicalismo es una institución clave de la sociedad y que el porvenir de esta depende de manera importante de que los intereses de los trabajadores sigan siendo representados por una institución como el sindicato, pero a tono con las necesidades futuras de nuestra sociedad.

Después de esta Introducción, en la segunda sección se examinará la globalización, los temas en debate, y se resaltarán cinco hechos clave que la caracterizan. En la tercera se analizarán los papeles tradicionales del sindicalismo y cómo estos han ido evolucionando, la percepción de la globalización que tienen los trabajadores y las tendencias internacionales (generalmente declinantes) de la sindicalización y sus efectos. En la cuarta y última sección se prestará atención al impacto de la globalización en los sindicatos de los países en desarrollo (el "Sur"), especialmente en América Latina, y se intentará dilucidar las implicancias de la globalización para el sindicalismo, a objeto de poder seguir siendo un agente de peso en la sociedad.

\section{II}

\section{Las tendencias a la globalización}

\section{1. ¿Qué se entenderá por globalización?}

Una definición sucinta la describe como una situación en que "se compite por todo, con todos y en todo el mundo". Más formalmente la globalización se puede describir como el proceso en que la producción de un país depende no tanto de la política económica y las condiciones nacionales, sino que el aparato productivo está cada vez más abierto a, y dependiente de, factores externos a él: dependiente de flujos de capital, mano de obra (migración) y tecnología que, junto con el intercambio creciente de bienes y servicios, determinan lo que se produce y consume, lo que se importa y exporta.

\section{El debate ${ }^{1}$}

En el principal debate en torno de la globalización se discute si esta es una tendencia positiva o negativa. Se critica que ella obliga a "competir hacia abajo". Es decir, que la necesidad de competir internacionalmente obliga a los países a reducir sus estándares nacionales a los estándares más bajos prevalecientes en el mundo. De ahí que haya una competencia por bajar salarios (al

\footnotetext{
${ }^{1}$ Una buena introducción al debate sobre la globalización la aportan Micklethwait y Wooldridge (2000). Entre las críticas más agudas pero ponderadas se puede recomendar a Gray (1998) y Stiglitz (2003). Una defensa acérrima de la globalización es la de Bhagwati (2004).
} 
menos no subirlos), reducir los estándares laborales y ambientales y cobrar menores impuestos a las empresas. A esta crítica económica se suma la crítica cultural, según la cual la globalización amenaza con poner fin a las idiosincrasias propias de cada nación, imponiéndose la cultura predominante, la estadounidense, a la nacional. Es lo que se denomina la "McDonaldización" del mundo.

Por el contrario, los defensores de la globalización dicen que es un proceso que beneficia a todos los países, no solo a los desarrollados, sino también - y sobre todo- a los países en desarrollo, ya que ayudará a acelerar su crecimiento. En defensa de su punto de vista, esgrimen el hecho de que las empresas multinacionales suelen pagar mejores salarios que las empresas locales; tener estándares laborales y ambientales superiores a los exigidos por las leyes nacionales; ser más cumplidoras de sus obligaciones en estas materias; y evadir menos impuestos que las empresas locales. A su vez, gracias a la apertura comercial que acarrea la globalización, el consumidor nacional consigue un producto de mejor calidad y a menor precio. En cuanto al aspecto cultural, se insiste en que, con todo, la cultura local domina los medios (programas de TV), en tanto que lo extranjero es secundario y las más de las veces enriquece, con su diversidad, en lugar de homogeneizar.

Este debate es demasiado denso e intenso como para pretender resolverlo en este artículo. De todos modos, nos atreveríamos a emitir dos juicios generales al respecto. Primero, si bien puede ser atractivo invertir en el Sur para aprovechar sus menores estándares laborales y ambientales, es probable que este escenario sea transitorio. En efecto, tarde o temprano la propia globalización tenderá a que sea obligatorio elevar los estándares del Sur, puesto que los países desarrollados exigirán cada vez más esta condición para mantener abiertos sus mercados a las exportaciones provenientes del Sur. En consecuencia, se exigirá a los países de América Latina cumplir con la legislación ambiental y laboral y no obviarla tal si fuera letra muerta, como a veces es el caso, haciendo la vista gorda al respecto.

En segundo lugar, en este debate ambas partes exageran mucho. Puede que la globalización no sea un juego de suma mayor a cero, como afirman sus defensores, pero tampoco es un juego de suma negativa, como sugieren algunos de sus detractores. Por ejemplo, en la discusión sobre el Tratado de Libre Comercio de América del Norte entre México y los Estados Unidos, sus detractores argumentaban que tanto los mexicanos como los estadounidenses iban a salir perdiendo. El temor de muchos en los Estados Unidos, como el can- didato presidencial Ross Perrot, era que las empresas estadounidenses se instalaran en México para aprovechar su mano de obra mucho más barata. Por lo tanto, el Tratado perjudicaría a los Estados Unidos en beneficio de México. A su vez, el temor de muchos mexicanos era el inverso: ¿Cómo iban a poder sobrevivir las empresas mexicanas teniendo que competir con importaciones producidas por empresas estadounidenses de mucho mayor productividad? Por consiguiente, el Tratado beneficiaría a los Estados Unidos a expensas de México. Obviamente, ambos argumentos se contradicen y no pueden ser ciertos en general. ${ }^{2}$

Por otra parte, también exageran aquellos defensores de la globalización que la describen casi como una panacea para los países emergentes. Por importante que la apertura de mercados sea para el desarrollo económico del Sur, lo decisivo es lo que se hace para elevar su escuálida productividad. Eso no viene de afuera, sino que depende esencialmente del esfuerzo interno.

Conviene repetir que si bien es imposible pretender resolver este debate en este artículo, de todos modos es importante tenerlo en cuenta al analizar los hechos clave de la globalización que resaltaremos, pues contextualiza $\mathrm{y}$ condiciona las posibles implicancias.

\section{Cinco hechos clave}

Como es sabido, las enormes disparidades en ingreso y productividad entre los países desarrollados del "Norte" y los países en desarrollo del "Sur" se deben a que el Norte abunda en capital y tecnología moderna y escasea en mano de obra. En cambio, el "Sur" se caracteriza por lo inverso: escasea el capital y predominan tecnologías atrasadas mientras que abunda, relativamente, la mano de obra. En teoría, superar estas brechas requiere llevar capital y tecnología del Norte al Sur y mover mano de obra del Sur al Norte. Esto se puede hacer directamente mediante flujos de capital, mano de obra y tecnología, así como por medios indirectos, es decir, por la vía del intercambio de bienes, donde el Sur exporta su exceso

\footnotetext{
2 Más bien, parecería que exportarían a México aquellas empresas estadounidenses cuya ventaja productiva es superior al diferencial salarial con México; mientras que exportarían a los Estados Unidos las empresas mexicanas cuyo diferencial en productividad no es tan grande como el diferencial salarial. De ahí que en ambos países se expandirán las empresas y actividades relativamente más productivas y declinarán las relativamente menos productivas. Si bien, en términos netos, esto puede ser positivo, habrá ganadores y perdedores en ambos países. Por lo demás, las ganancias no necesariamente serán parejas para ambos, de ahí la necesidad de una buena negociación, así como de una política económica nacional a tono con las necesidades del desarrollo.
} 
de mano de obra en la forma de bienes altamente intensivos en ella.

La globalización apunta en esta dirección. Mas, anticipándonos a las conclusiones que vienen, por avanzada que sea la globalización, los flujos actuales son muy inferiores a los requeridos para reducir rápidamente estas brechas de ingreso y productividad. Más aún, observaremos una importante asimetría entre los distintos flujos, donde unos son altamente significativos (el intercambio de bienes), otros son escasos (los flujos migratorios y de tecnología) y otros ocupan un lugar intermedio (los flujos de capital).

El primer hecho se refiere a la creciente importancia del comercio internacional, es decir, de los flujos de bienes entre los países. En el gráfico 1 se muestra el crecimiento del volumen de las exportaciones, así como del producto interno bruto (PIB) del mundo desde 1870: primero, desde 1870 a 1950 y, segundo, desde 1950 al presente. Se observa que entre 1870 y 1950 las exportaciones y el PIB crecieron en forma similar, ambos más o menos quintuplicándose en el período. Sin embargo, en el segundo período, desde 1950 al presente, se han disparado las exportaciones. Estas se han multiplicado 22 veces en comparación con un aumento importante (71/2 veces) pero menor del PIB. De modo que en el período entero de 1870 al presente, mientras el PIB mundial se ha multiplicado 36 veces en esos 138 años, es decir, a una tasa cercana al 2,6\% anual, las exportaciones han crecido 130 veces, esto es, a una tasa del orden del $3,6 \%$ anual.

En consecuencia, el peso de las exportaciones en el PIB se ha cuadriplicado ampliamente de un 5\% del PIB en 1870 al 23\% del PIB en 2008 (véase el gráfico 2). Si bien este es un crecimiento extraordinario, cabe señalar que, no obstante, las tres cuartas partes de lo que se produce cada año siguen siendo consumidas domésticamente. Y es así, puesto que gran parte de la producción anual está constituida por bienes difíciles o imposibles de exportar. En la práctica, no son bienes o servicios transables internacionalmente la gran mayoría de los gastos en salud, educación, gobierno, comercio, servicios y construcción, que constituyen típicamente el $60 \%$ del PIB de cada país.

Este mayor intercambio comercial internacional ha obedecido a múltiples factores. Entre los más importantes están las fuertes reducciones en los costos de transporte, tanto entre 1870 y 1950 como entre 1950 y el presente. En segundo lugar y desde la Segunda Guerra Mundial, se desarrolla el proceso de integración económica europea, que culmina en su mercado común y una moneda única. En tercer término, y nuevamente desde 1950, tienen lugar las distintas rondas de reducciones

GRÁFICO 1

Crecimiento de exportaciones y PIB del mundo, desde 1870 al presente (Índice $1950=100$ )
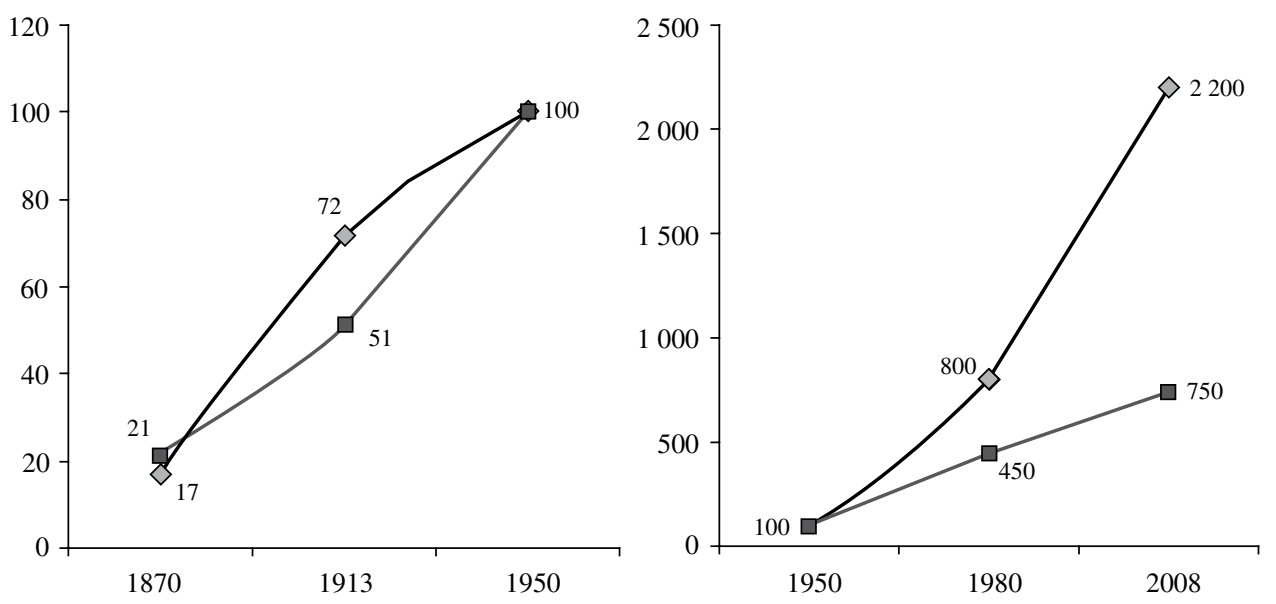

$$
\begin{array}{ll}
\neg \text { Exportaciones : } & 130 \text { veces } \\
\neg-\text { PIB } \quad: 36 \text { veces }
\end{array}
$$

Fuente: Angus Maddison, The World Economy: A Millennial Perspective, París, Organización de Cooperación y Desarrollo Económicos (OCDE), 2001, y actualizaciones del autor a partir de 1998.

Nota: Para efectos de visualización se separan los períodos 1870-1950 y 1950-2008. 


\section{Exportaciones como porcentaje del PIB, desde 1870 al presente}

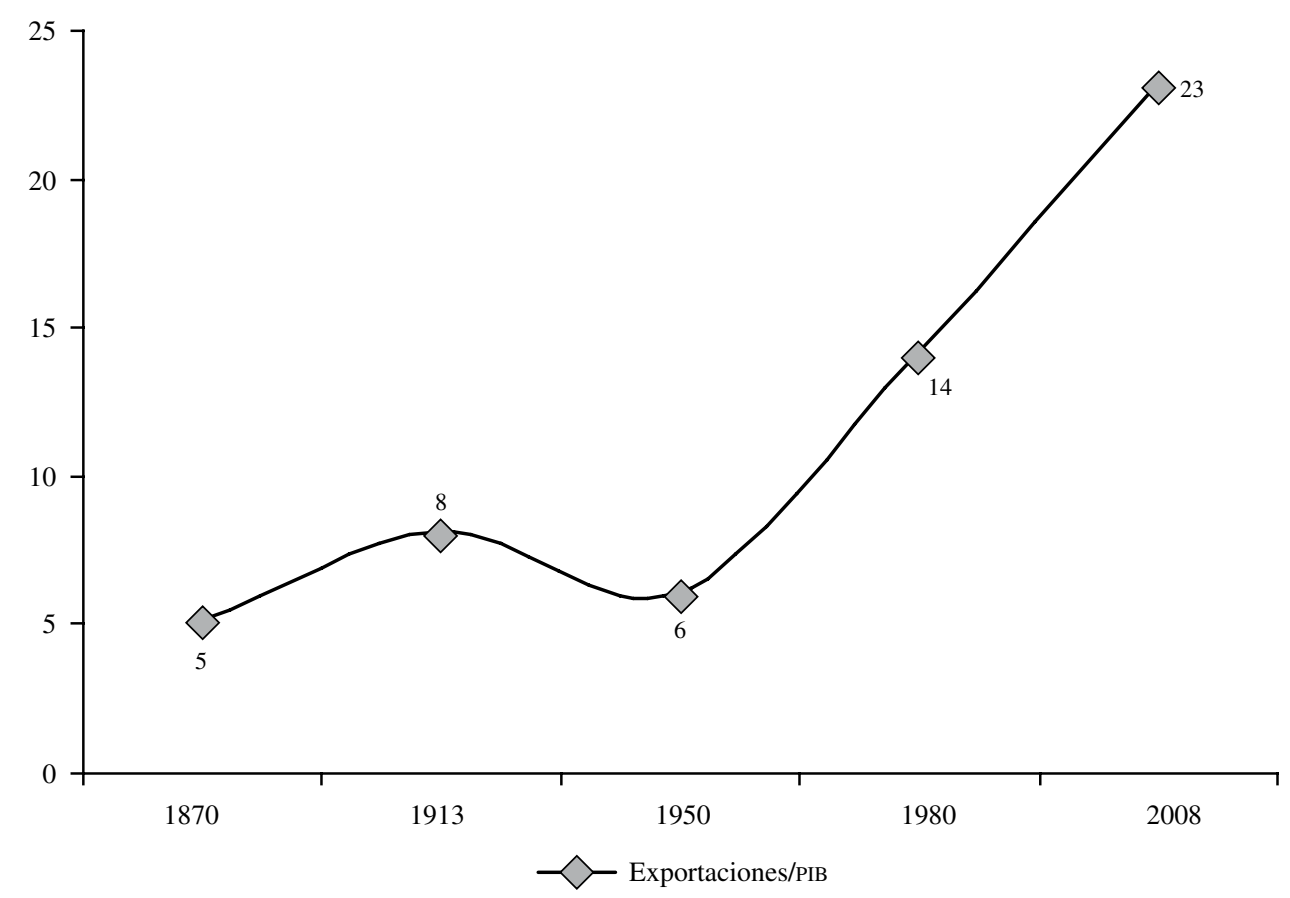

Fuente: Angus Maddison, The World Economy: A Millennial Perspective, París, Organización de Cooperación y Desarrollo Económicos (ocDE), 2001, y actualizaciones del autor a partir de 1998.

Nota: Para efectos de visualización se separan los períodos 1870-1950 y 1950-2008.

arancelarias multilaterales promovidas por el Acuerdo General sobre Aranceles Aduaneros y Comercio (GATT), después de alzas significativas en los aranceles en el período comprendido entre las dos guerras mundiales. Finalmente, se alcanzan los múltiples acuerdos bilaterales y subregionales de integración económica de finales del siglo XX y principios del siglo XXI.

En América Latina este fenómeno de mayor intercambio comercial ha sido coadyuvado por las políticas de apertura comercial impulsadas en los años ochenta, después de la crisis de la deuda externa en que los países de la región efectuaron un "viraje estratégico", pasando de una estrategia de industrialización sobre la base de una alta protección arancelaria y la sustitución de las importaciones a un modelo exportador con bajos aranceles. En efecto, el arancel promedio de la región pasó de cerca del $30 \%$ a principios de la década de 1980 a un $10 \%$ en la actualidad (véase el cuadro 1). Asimismo, se han firmado o profundizado un sinnúmero de acuerdos comerciales bilaterales y subregionales. En consecuencia, en América Latina el peso de las exportaciones en el PIB ha pasado del orden de un $13 \%$ en 1980 a cerca del $25 \%$ en la actualidad.
No obstante, cabe notar que el grueso del comercio internacional no es entre países desarrollados, que exportan productos industriales, y países en vías de desarrollo, que exportan materias primas, sino entre el Norte y el propio Norte, intercambiándose distintos productos industriales. Así, el 77\% de las exportaciones del Norte van a otros países del Norte (véase el cuadro 2) y solo el $23 \%$ van al Sur. Es así, pese a lo que se podría haber pensado inicialmente, puesto que se exporta más a los mercados con mayor poder de compra. Asimismo, buena parte de las "ventajas comparativas" del Norte no residen tanto en industrias intensivas en capital como en aquellas intensivas en conocimiento. Y el Norte, sin lugar a dudas, genera la mayor parte del conocimiento en la actualidad. Es por estas dos razones que el grueso de las exportaciones del Norte se realizan al propio Norte.

Precisamente porque el intercambio de bienes induce a que cada país se especialice en aquello en que es relativamente más eficiente, también permite que países abundantes en materia prima y mano de obra, como los del Sur, exporten parte de esa abundancia a los mercados del Norte por medio de bienes intensivos en materia prima y mano de obra. No obstante, como buena parte 
CUADRO 1

Reducciones arancelarias en América Latina, 1980-2006

(En porcentajes)

\begin{tabular}{lccc}
\hline País & Mediados de años ochenta & 2006 & Puntos de reducción \\
\hline Argentina & 28 & 12 & -16 \\
Brasil & 52 & 9 & -43 \\
Chile & 20 & 6 & -14 \\
Colombia & 28 & 12 & -16 \\
Ecuador & 28 & 9 & -19 \\
México & 12 & 11 & -1 \\
Perú & 40 & 7 & -33 \\
Venezuela (Rep. Bol. de) & 33 & 15 & -18 \\
América Latina & 30 & 10 & -20 \\
\hline
\end{tabular}

Fuente: Organización Mundial del Comercio (omc), Perfiles arancelarios en el mundo 2008, Ginebra, 2008.

CUADRO 2

Flujos de comercio internacional

(En billones de dólares)

\begin{tabular}{|c|c|c|c|c|}
\hline Flujos de comercio & $\begin{array}{l}\text { Mundo } \\
\text { importa }\end{array}$ & $\begin{array}{l}\text { Países desarrollados } \\
\text { importan }\end{array}$ & & $\begin{array}{c}\text { Países en desarrollo importan } \\
\text { (América Latina) }\end{array}$ \\
\hline Mundo exporta & 13,9 & 9,8 & & $\begin{array}{l}4,1 \\
(0,75)\end{array}$ \\
\hline Países desarrollados exportan & $\begin{array}{c}9,8 \\
71\end{array}$ & 7,5 & 77 & $\begin{array}{l}2,3 \\
(0,54)\end{array}$ \\
\hline Países en desarrollo exportan & $\begin{array}{l}4,1 \\
29\end{array}$ & 2,3 & 56 & $\begin{array}{l}1,8 \\
(0,21)\end{array}$ \\
\hline
\end{tabular}

Fuente: Banco Mundial, Informe sobre el desarrollo mundial 2009, Washington, D.C., 2009. World Development Report 2009 (WB).

de la producción de materia prima es intensiva en capital (la minería y la energía, por ejemplo), en términos netos nuestra exportación no es particularmente intensiva en mano de obra. De ahí que nuestras exportaciones sean un sustituto muy imperfecto del movimiento de factores, es decir, de la migración de mano de obra desde el Sur, donde abunda, hacia el Norte, donde escasea, y del movimiento de capital en sentido inverso, desde el Norte, donde abunda, hacia el Sur, donde escasea.

Sin lugar a dudas, la magnitud de los flujos de bienes y servicios hace que las exportaciones y la apertura comercial hayan sido el hecho más sobresaliente de la globalización.

El segundo hecho, que sigue en importancia al intercambio comercial, es el flujo de capitales entre los países y —más concretamente— la inversión extranjera directa (IED). En el cuadro 3 se indica que cada año se están invirtiendo del orden de 1,8 billones de dólares en forma de IED fuera del país de origen. Tal como cabría esperar, el $90 \%$ de esa inversión se origina en los países desarrollados. Sin embargo, y a diferencia de lo que podría pensarse, el grueso de esa inversión (dos terceras partes) se dirige a otros países desarrollados del Norte, también abundantes en capital, y no a los países en desarrollo, escasos de capital, que reciben el tercio de esa inversión. La razón de ello es que la IED no solo se mueve con el fin de extraer recursos naturales para luego transformarlos -el caso típico de la IED en el Sur-, sino que se instala también, y en forma incluso más importante, para aprovechar la cercanía a los grandes mercados, sobre todo en el Norte. De ahí que la IED en el Sur suele proponerse la extracción de recursos naturales, cobre por ejemplo, para posteriormente transformarlos en productos industriales tales como cables eléctricos. En cambio, el objetivo característico de la localización de la IED en el Norte es instalarse cerca de los grandes mercados, como es el caso de las plantas automotrices japonesas en los Estados Unidos o las estadounidenses 
CUADRO 3

Inversión extranjera directa en el mundo, 2007

(En billones de dólares)

\begin{tabular}{lccc}
\hline Inversión extranjera directa (IED) & Mundo recibe & Países desarrollados reciben & $\begin{array}{c}\text { Países en desarrollo reciben } \\
\text { (América Latina) }\end{array}$ \\
\hline Mundo invierte & 1,8 & 1,2 & 0,6 \\
& & & $0,125)$ \\
Países desarrollados invierten & 1,7 & 0,115 & 0,55 \\
Países en desarrollo invierten & 0,1 & 0,05 & 0,05 \\
\hline
\end{tabular}

Fuente: Banco Mundial, Informe sobre el desarrollo mundial 2009, Washington, D.C., 2009. World Development Report 2009 (wB).

en Europa. Ello explica que la mayor parte de la IED sea entre países desarrollados.

De todas maneras, conviene señalar que la IED en los países en desarrollo ha estado creciendo en forma veloz: de 6.000 millones de dólares en 1980 en América Latina a 20 veces ese valor en la actualidad (véase el cuadro 4). Esto es tanto o más importante si se considera que es probable que la IED traiga consigo más y mejores tecnologías que la inversión nacional, por lo que la inversión extranjera se ha constituido en un factor relevante en el desarrollo del Sur. Sin embargo, hay que reconocer que aún representa menos de un quinto de la inversión realizada anualmente en América Latina, y un porcentaje incluso menor (apenas un 3,7\%) del PIB de la región, lo que denota que la movilidad internacional de factores está lejos de ser lo que predicen los libros de texto.

En efecto, el $90 \%$ de la inversión total mundial sigue teniendo una marcada tendencia "insular", es decir, se efectúa en el propio país. Pese a que es probable que existan mayores oportunidades de inversión en las economías emergentes del Sur que en los mercados maduros del Norte, la gran mayoría de las empresas siguen prefiriendo invertir en su mercado nacional. Esta tendencia "no globalizadora" obedece a múltiples motivos: porque los empresarios conocen mejor las oportunidades en sus propios mercados, porque están más circunscritas por la propia legislación, o porque el empresario no está dispuesto a capitalizar lo necesario para internacionalizarse, pues al hacerlo se diluiría su control sobre la empresa.

Como consecuencia de esta "insuficiente globalización" productiva por parte del capital del Norte, al no aprovechar las amplias oportunidades presentes en el Sur y destinar un menor flujo de IED hacia esa región, se reduce la rentabilidad potencial del capital del Norte. Pero, por sobre todo, se perjudica a la abundante mano de obra del Sur, que está obligada a trabajar en empresas
CUADRO 4

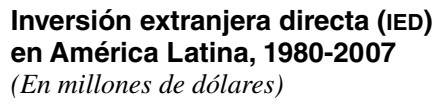

\begin{tabular}{lccc}
\hline & 1980 & 2004 & 2007 \\
\hline IED en América Latina & 5700 & 60000 & 126300 \\
IED/PIB & $0,4 \%$ & $3,0 \%$ & $3,7 \%$ \\
IED/inversión total & $2,0 \%$ & $15,0 \%$ & $17,8 \%$ \\
\hline
\end{tabular}

Fuente: Conferencia de las Naciones Unidas sobre Comercio y Desarrollo (UNCTAD), Informe sobre las inversiones en el mundo, 2008 (UNCTAD/WIR/2008), Nueva York, 2008. Publicación de las Naciones Unidas, $\mathrm{N}^{\mathrm{o}}$ de venta: E.08.II.D.3; y Comisión Económica para América Latina y el Caribe (CEPAL), La inversión extranjera directa en América Latina y el Caribe, 2008 (LC/G.2406-P), Santiago de Chile, 2008. Publicación de las Naciones Unidas, $\mathrm{N}^{\circ}$ de venta: S.09.II.G.24.

locales de baja intensidad de capital y de tecnología atrasada y, por ende, con bajos niveles salariales y de productividad.

Esto es así pese a que, como señalan muchos críticos de la globalización y la IED, muchas empresas vienen al Sur para aprovechar los bajos salarios. En efecto, si bien su motivación puede ser aquella, mientras más llegan a instalarse, mayor es la demanda por trabajo y, eventualmente, más ostensible la presión para elevar los salarios locales. Es lo que ha ocurrido en Japón que empezó con industrias altamente intensivas en mano de obra y escuálidos salarios, pero que con los años y la mayor inversión redujo cada vez más la abundancia de mano de obra, lo que permitió elevar los salarios (y la productividad), de modo que hoy el Japón paga salarios superiores a los de los Estados Unidos. Este mismo fenómeno se produjo en la República de Corea y en la provincia china de Taiwán y se está dando en China y en la India. A la larga, entonces, la IED contribuye a reducir la abundancia de mano de obra y elevar los salarios, pero este efecto no es ni inmediato ni automático. Depende 
de la política implementada en la región y del poder de los sindicatos el afianzarlo. ${ }^{3}$

Por cierto, estas repercusiones no dependen exclusivamente de la IED, sino que son fruto, en general, de todo tipo de inversión, tanto nacional como extranjera, la que ha de ser alentada. Sin embargo, como la IED destinada al Sur es todavía relativamente baja (1/3 del total) y la que hay se concentra en relativamente pocos países (China, Brasil, entre otros), existe un amplio espacio para orientarla a los demás países. Por otra parte, como la IED suele traer consigo mejores tecnologías, también suele crear puestos de trabajo de mayor productividad y nivel salarial. De ahí que sea importante para el sindicalismo en la región propiciar tanto una mayor inversión general como un flujo más elevado de IED hacia el Sur. Más IED implica ampliar el grado de libertad de los países del Sur y de sus sindicatos — posibilitando una potencial mayor productividad y un mejoramiento salarial—, opción que no existirá si la IED se incorpora en forma poco significativa a estos países, como hasta ahora ha sido el caso para la mayoría de las economías del Sur.

La tercera vía que adopta la globalización es la migración de mano de obra, tal vez la manera potencialmente más directa y rápida de elevar ingresos y productividad en el mundo, llevando la mano de obra desde donde abunda (el Sur) hacia donde escasea (el Norte). No obstante, como veremos en seguida, es la vía relativamente menos utilizada $\mathrm{y}$, a la vez, la menos discutida. Y cuando se discute, es quizás la que más emociones despierta tanto en el Norte como en el Sur.

No es que no haya migración, sino que esta procede a paso de tortuga. Tal como se indica en el cuadro 5, la migración ocurre principalmente desde países en vías de desarrollo hacia países desarrollados. Sin embargo, tal como se indica en el cuadro 6 , el total de migrantes anuales (legales al menos) si bien representa una gran cifra en términos absolutos: 2.600 .000 al año, se trata de una cifra baja si se la compara con el crecimiento demográfico anual: apenas un 3,2\% del incremento poblacional mundial y solo un $3 \%$ del crecimiento anual de la población del Sur. A título de ejemplo y comparación, se estima que un tercio del incremento poblacional

\footnotetext{
${ }^{3}$ Tal vez por esta razón es que en la mayor parte de los estudios se constata que los salarios pagados en las empresas transnacionales del Sur son significativamente superiores a los salarios locales. O pagan mejor por traer estándares más elevados desde sus países de origen o lo hacen para tener una mayor productividad, de modo que nuestros sindicatos pueden captar parte de esta renta mediante una buena negociación. Véanse de nuevo Micklethwait and Wooldridge (2000) y Brown, Deardorff y Stern (2003).
}

europeo en el siglo XIX pudo ser absorbido gracias a la migración al Nuevo Mundo. ${ }^{4}$ Por lo tanto, una cifra parecida requeriría un incremento $¡ 10$ veces mayor! en la actual migración del Sur al Norte.

Como ya se dijo, el tema está minado de emoción y por ambos lados. Si bien la migración actual corresponde a un bajo porcentaje del crecimiento poblacional de los países en desarrollo, dado el virtual estancamiento demográfico del Norte, la migración del Sur representa el 54\% del crecimiento poblacional del Norte (en verdad equivale a más del $100 \%$ del crecimiento poblacional europeo y japonés, y solo representa un porcentaje más bajo en los Estados Unidos y Oceanía). De ahí que muchos en el Norte resientan que esta mano de obra les quite sus trabajos y haga bajar sus elevados salarios, por lo que existe una fuerte presión nacionalista para frenar la migración, tanto la legal como, desde luego, la ilegal.

En cuanto al Sur, hiere el orgullo que tantos connacionales tengan que abandonar la patria en busca de mejores destinos en el exterior. A su vez, existe la preocupación en el Sur de que se produzca una "fuga de cerebros o talentos", perdiéndose aquello en que más se invirtió y que más necesita el país.

No obstante estas legítimas inquietudes, hay que contrastar los beneficios de la migración. Primeramente, suele haber un incremento significativo en el nivel de vida de los propios migrantes, tanto en ingresos como en salud y aprendizaje. Y el beneficio es relativamente mayor cuando menos calificado es el emigrante. En efecto, si bien los salarios en el Norte son superiores a los del Sur en todas las profesiones y oficios, el salto es particularmente grande para la mano de obra poco calificada, ya que esta gana en torno de la subsistencia en el Sur, mientras que en el Norte recibe un ingreso decoroso para esa realidad y "millonario" en comparación con el Sur. Aunque las diferencias subsisten para los profesionales, son sustancialmente menores, sobre todo cuando se ajustan por diferencias efectivas en costo de vida.

En segundo término, hay un efecto positivo para los que no migran. Por una parte, la migración reduce la competencia para los escasos buenos trabajos locales. Por otra, los emigrantes suelen enviar remesas a sus familiares en el Sur. Se estima que el año pasado las remesas al Sur fueron de 328.000 millones de dólares, vale decir, dos veces y media la ayuda externa de los países de la Organización de Cooperación y Desarrollo

\footnotetext{
${ }^{4}$ Estimación basada en Maddison (2001).
} 
CUADRO 5

Flujos migratorios, 2000-2005

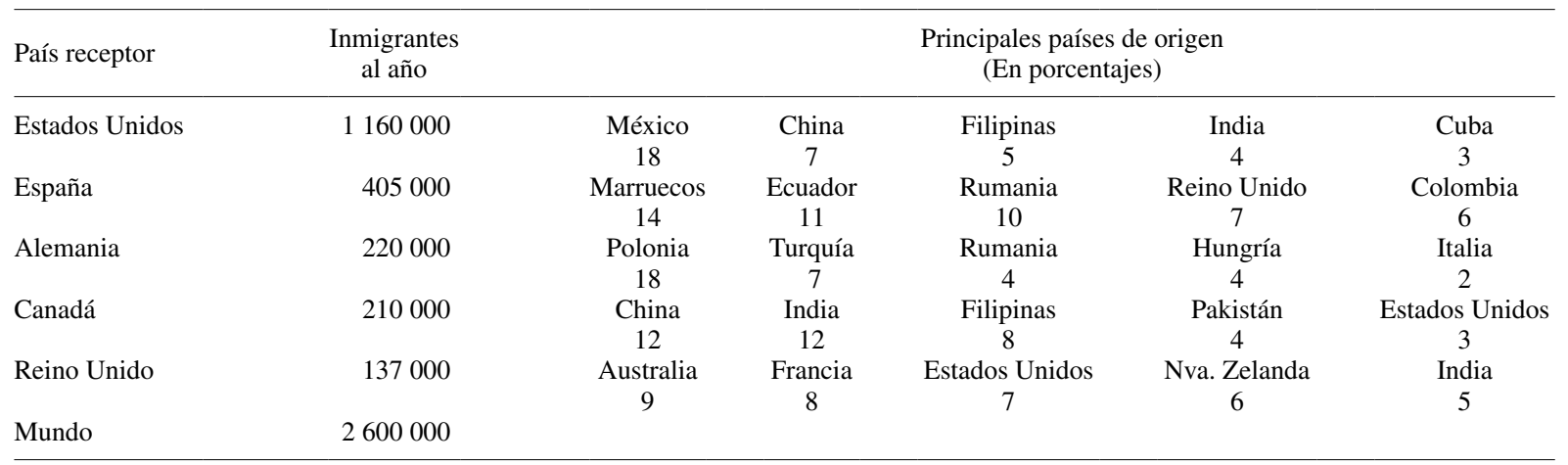

Fuente: Naciones Unidas, International Migration Report 2006: A Global Assessment (ESA/P/WP.209), Nueva York, 2006.

Nota: Promedios 2000-2005.

CUADRO 6

Importancia relativa de la migración según grado de desarrollo

\begin{tabular}{lccr}
\hline & Mundo & Países desarrollados & Países en desarrollo \\
\hline Inmigración (Millones de personas al año) & 2,6 & 2,6 & $-2,6$ \\
Población (Millones de habitantes) & 6500 & 1200 & 5300 \\
Crecimiento poblacional (Millones de personas al año) & 82 & 5 & 77 \\
Porcentaje de población & $1,3 \%$ & $0,4 \%$ & $1,5 \%$ \\
Inmigración (Como porcentaje de crecimiento poblacional) & $3,2 \%$ & $54 \%$ & $-3 \%$ \\
\hline
\end{tabular}

Fuente: Naciones Unidas, International Migration Report 2006: A Global Assessment (ESA/P/WP.209), Nueva York, 2006.

Económicos (OCDE). ${ }^{5}$ Por ejemplo, ¡las remesas de los indios en el exterior fueron superiores a la IED en la India ese año! Y no solo hay remesas en dinero, sino que hay "remesas" de ideas. Al respecto, existe evidencia de que por esta vía se produce una importante transferencia de conocimiento. Por ejemplo, parte del éxito de la aglomeración productiva (cluster) informática de Bangalore, en la India, se debe a ingenieros indios que trabajaban en Silicon Valley y que transfirieron sus conocimientos al montaje de negocios similares en Bangalore. En menor escala, se observan fenómenos análogos con emigrantes africanos y centroamericanos que vuelven a sus países de origen con capital e ideas para llevar a cabo sus proyectos.

Debido a razones como las anteriores, en el último Informe sobre desarrollo humano de las Naciones Unidas

${ }^{5}$ Véase "Migration and development: the aid workers who really help", en The Economist, 10 de octubre de 2009. se concluyó que la migración era un beneficio neto tanto para los que emigran como para los que se quedan en sus países de origen; y que sin duda era también claramente beneficiosa para los propios países receptores. ${ }^{6}$

Sin embargo, existen fuertes barreras a la migración, sobre todo para personas de baja calificación, precisamente quienes más se benefician de la posibilidad de migrar. La migración sigue siendo vista como un fenómeno que cada país tiene el legítimo derecho de frenar. Y a diferencia de los aranceles aduaneros o barreras contra el ingreso o salida de capitales, no solo se reconoce el derecho de los países a frenar la migración, sino que hay poca conciencia de que pudiera ser un deber eliminar tales barreras a la migración. De ahí la importancia de este último Informe de desarrollo humano en que se aboga por reducir y liberalizar las barreras contra la inmigración,

\footnotetext{
${ }^{6}$ Naciones Unidas (2009).
} 
sobre todo de personas de baja calificación. ${ }^{7}$ Hasta ahora no ha habido ninguna instancia internacional que trabaje en pos de reducir cada vez más las restricciones a la inmigración, como sí las hay para alentar el comercio y los flujos de capital. Por tanto, este es un campo que amerita una acción decidida de parte del sindicalismo del Sur, ya que la emigración de mano de obra poco calificada puede aliviar significativamente la presión negativa sobre los mercados de trabajo del Sur.

Una cuarta forma que adquiere la globalización es la imitación, compra y transferencia de mejores prácticas y tecnologías. Así, más del $80 \%$ de las patentes se generan en los países desarrollados y presumiblemente algo similar ocurre con las innovaciones no patentadas. Por consiguiente, es razonable suponer que el grueso de la transferencia tecnológica será de Norte a Sur. Más aún, dados los enormes desniveles en productividad existentes entre ambos, cabría esperar flujos importantes de transferencia.

Parte de esta transferencia se produce a través de la compra de equipos que incorporan mejoras tecnológicas. De hecho, casi la mitad de la inversión en capital fijo se realiza en equipos y maquinaria, por lo que cerca del 10\% del PIB que ella representa corresponde a equipamiento importado, con tecnología moderna. Otra parte del flujo tecnológico consiste en la imitación (inteligente) y adaptación local de las mejores prácticas internacionales (por ejemplo, se copia la idea de malls o de mini markets o de producción "justo a tiempo" (just-in-time) sin necesidad de pagar nada). Finalmente, otra parte se da a través del pago de regalías (royalties) por licencias y franquicias.

Dadas las enormes brechas de productividad y atraso tecnológico de los países en desarrollo, podría esperarse que los países emergentes compraran tecnología en grandes volúmenes. De hecho, tal como habría de esperarse, la compra tecnológica es dos veces y media mayor en países emergentes exitosos como la República de Corea, Portugal y España (gastan del orden de $0,5 \%$ del PIB en tales compras) que la compra de tecnología entre los propios países desarrollados (véase el cuadro 7). En cambio, a diferencia de lo que cabría esperar, sucede lo contrario en América Latina. $\mathrm{Al}$ respecto, llama la atención que, salvo en Argentina, el pago por royalties como porcentaje del PIB en los países

\footnotetext{
${ }^{7}$ Véase Naciones Unidas (2009). En este Informe se aboga por un paquete de reformas de seis pilares que incluyen, entre otras, la liberalización y facilitación de la inmigración para personas de baja calificación, tanto para trabajos temporales como permanentes; el aseguramiento de los derechos básicos de los inmigrantes en los países de destino; y la reducción de los costos de transacción de la migración.
}

de América Latina es la quinta parte de lo registrado en los países emergentes exitosos. Sorprende aún más que la compra de tecnología en la región equivale a la mitad de la que se efectúa entre los países desarrollados ( $0,1 \%$ del PIB comparado a $0,2 \%$ del PIB en los países desarrollados).

Es decir, la transferencia tecnológica hacia América Latina dista de ser lo que podría y debería ser para economías como las de la región, tan lejos de la frontera tecnológica y de mejores prácticas internacionales. Como consecuencia de esta insuficiente transferencia tecnológica, tienden a persistir las enormes brechas de productividad $\mathrm{y}$, por ende, de ingresos que separan a América Latina de las economías desarrolladas.

Quinto, los países de desarrollo tardío tienen una, una sola, gran ventaja. Y es que una vez superadas las limitaciones institucionales y endémicas del subdesarrollo, podrían crecer a tasas mucho más elevadas que los primeros países en desarrollarse históricamente. En efecto, mientras más tarde parte el desarrollo en un país, mayor es la distancia que lo separa de la frontera tecnológica y, por tanto, puede crecer más rápidamente, saltando etapas de desarrollo, copiando y adaptando las tecnologías modernas que le sean más idóneas. Es el fenómeno conocido como catch up o recuperación del terreno perdido (véase el gráfico 3). Esto explica por qué Japón pudo crecer a tasas tan aceleradas desde fines del siglo XIX; y posteriormente, a partir de 1950,

CUADRO 7

Pagos por licencias para transferir tecnología (En porcentajes)

País/región Pago anual por licencias/PIB

\begin{tabular}{lc}
\hline América Latina & \\
México & 0,12 \\
Brasil & 0,08 \\
Chile & 0,10 \\
Argentina & 0,34 \\
& \\
Países desarrollados & \\
Europa & 0,28 \\
Japón & 0,20 \\
Canadá & 0,20 \\
Australia & 0,09 \\
& \\
Emergentes & \\
Corea & 0,50 \\
Portugal & 0,60 \\
España & 0,40
\end{tabular}

Fuente: Roberto Álvarez, Gustavo Crespi y Joseph Ramos, "The impact of licenses on a "late starter" LDC: Chile in the 1990s", World Development, vol. 30, № 8, Amsterdam, Elsevier, agosto de 2002. PIB: Producto interno bruto. 
GRÁFICO 3

\section{Convergencia (catch-upa): la gran ventaja potencial de un desarrollo tardío}

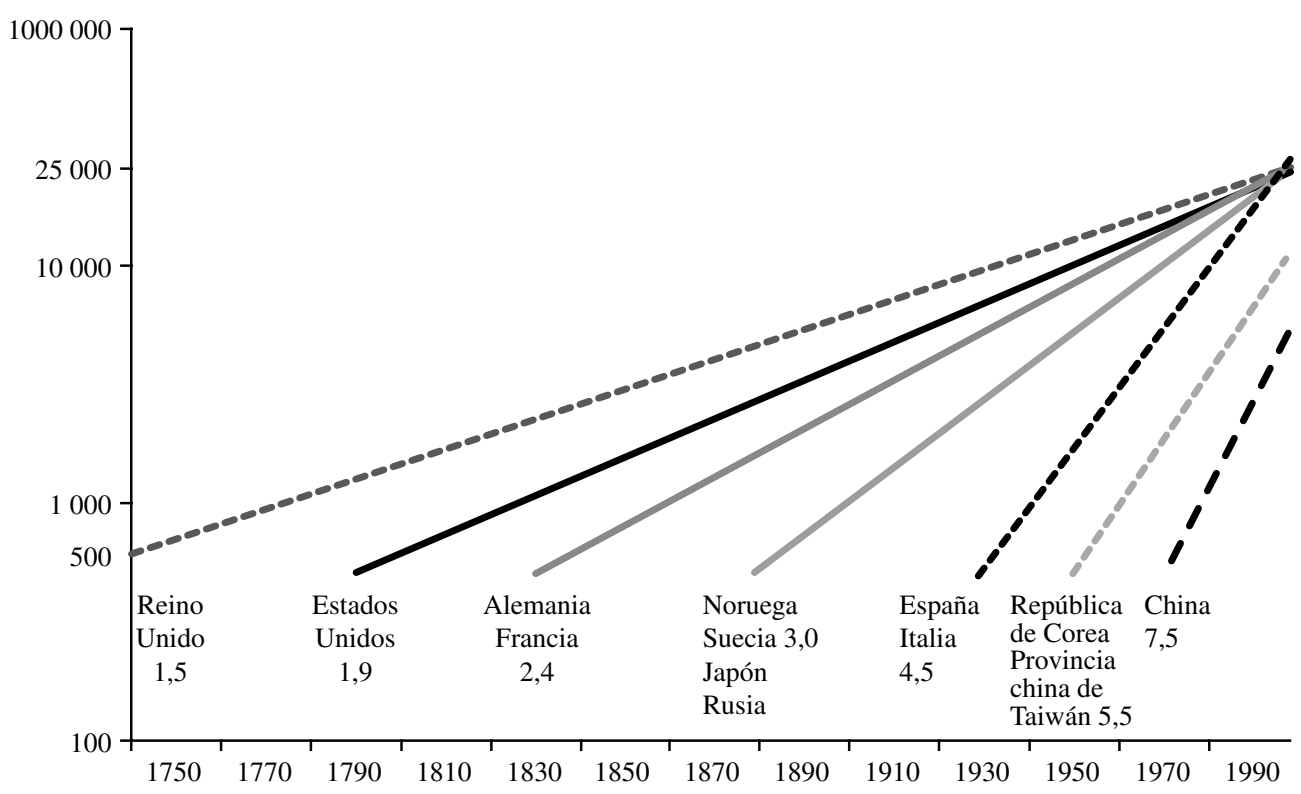

Fuente: elaboración propia sobre la base de Maddison (2001) Angus Maddison, The World Economy: A Millennial Perspective, París, Organización de Cooperación y Desarrollo Económicos (OCDE), 2001 y actualizaciones por el autor.

a Recuperar terreno perdido.

que los "tigres" crecieran incluso más rápido que Japón durante su milagro; y actualmente, que China continental crezca desde los años ochenta a tasas inauditas, sobre el 7,5\% per cápita, muy superiores a las de los "tigres" en su mejor época. Tampoco cabe duda que buena parte del "milagro chileno" de mediados de los años ochenta hasta la fecha se debe a que finalmente pudo aprovechar esta, la única gran ventaja de ser un país de desarrollo tardío.

Sin embargo, en lugar de cerrarse las brechas tecnológicas y de mejores prácticas con los países desarrollados, la productividad en América Latina, salvo el caso de Chile, creció menos que la de los países desarrollados entre 1980 y el presente, por lo que la frontera tecnológica se alejó aún más. ${ }^{8}$ Ello muestra lo mucho que habría que hacer en este ámbito. Nuevamente hay que insistir en que la posibilidad de tener trabajos decentes, con salarios dignos, requiere de niveles de productividad mucho más elevados que los que actualmente caracterizan a los países de la región.

\footnotetext{
${ }^{8}$ Véase Castaldi y otros (2009).
}

Para alcanzar esos objetivos, un factor principal es la transferencia de tecnologías y mejores prácticas, incluso más que el intercambio comercial, la IED y la migración. ${ }^{9}$ Es este el flujo potencial que efectivamente está por explotarse en el futuro en los países en desarrollo, y en América Latina, en particular. De hecho, por mucho que critique la globalización, Stiglitz insiste en que es esta capacidad - la de identificar las tecnologías y prácticas más idóneas para sus países, para luego adaptarlas, asimilarlas y difundirlas - la que explica en última instancia el milagro japonés, el de los "tigres asiáticos"

\footnotetext{
${ }^{9}$ Por cierto, nada de esto arguye en contra de la investigación e innovación domésticas. En efecto, en la actualidad la región invierte poco en investigación y desarrollo (I\&D): del orden de $0,6 \%$ del PIB. Si bien es cierto que en la actual etapa de desarrollo de América Latina será más importante la transferencia tecnológica que el desarrollo tecnológico propio, se necesita hacer algo de I\&D para poder asimilar y adaptar las mejores prácticas y tecnologías internacionales. Por otra parte, si bien la mayoría de las empresas de la región están lejos de la frontera tecnológica, una parte de ellas, incluidas muchas de las exportadoras de recursos naturales, están cerca de dicha frontera, por lo que deben efectuar importantes inversiones en I\&D si pretenden mantener sus elevadas rentas.
} 
y, por cierto, actualmente, los milagros de China y la India. Fue esta capacidad de imitar, adaptar y asimilar tecnologías, mucho más que las políticas ortodoxas, neoliberales, lo que según él explica sus éxitos. ${ }^{10}$

En síntesis, un examen de la globalización, como el realizado hasta ahora, revela una gran conclusión: más que avanzar rápida o lentamente, la globalización ha avanzado en forma asimétrica, pues los ritmos de los flujos de bienes, capital, mano de obra y tecnología han sido muy disímiles.

i) A la fecha, la globalización ha avanzado en forma más rápida en lo que se refiere al intercambio de bienes, donde las exportaciones en América Latina han alcanzado el $25 \%$ del PIB. Le siguen en velocidad los flujos de IED, que llegan a representar el 18\% de la inversión anual que se realiza. En cambio, la globalización ha avanzado mucho menos en lo que a transferencia tecnológica y migración se refiere. Lamentablemente, es probable que sean estos dos últimos factores los que más rápida y directamente pudieran mejorar los niveles de vida de la región, caracterizada por una abundancia de mano de obra y puestos de trabajo de baja productividad.

\footnotetext{
${ }^{10}$ Véase Stiglitz (2003). De hecho, según este autor, hubo en ellas amplias divergencias con la doctrina neoliberal: fuerte intervención estatal sobre la base de grandes empresas nacionales (República de Corea); otros (provincia china de Taiwán) favorecieron, por razones militares, el desarrollo de medianas empresas; otros optaron por atraer a multinacionales (Singapur); otros se desarrollaron con un amplio sector estatal (China) tanto en el sistema productivo como, sobre todo, en el financiero. Y todas estas experiencias, hasta épocas recientes, convivieron con significativas barreras arancelarias.
}

La globalización es mucho mayor entre países desarrollados (Norte-Norte) que entre países desarrollados y en desarrollo (Norte-Sur). Entre dos terceras y tres cuartas partes de la IED y de las exportaciones, respectivamente, son entre países desarrollados.

iii) Solo la migración se produce principalmente entre Sur y Norte, pero avanza a ritmos poco significativos (3\% del crecimiento poblacional de los países en desarrollo), muy inferiores a los ritmos registrados en el siglo XIX en Europa.

En consecuencia (véase el cuadro 8), el mundo en desarrollo, que constituye el $81 \%$ de la población mundial, explica apenas el 26\% del PIB mundial. Es así ,pues solo efectúa el $19 \%$ de las patentes anuales y el $29 \%$ de las exportaciones, mientras que cuenta apenas con el 14\% de las empresas más grandes del planeta. El mundo en desarrollo solo pesa en población y en el porcentaje de materias primas que exporta (37\% del monto mundial).

CUADRO 8

\section{Asimetrías internacionales} (En porcentajes)

\begin{tabular}{lll}
\hline 1. & Población & 81 \\
2. & PIB & 26 \\
3. & Porcentaje de 500 mayores empresas & 14 \\
4. & Patentes & 19 \\
5. & Exportaciones & 36 \\
6. & Exportación de materias primas & 37 \\
\hline
\end{tabular}

Fuente: Conferencia de las Naciones Unidas sobre Comercio y Desarrollo (UNCTAD), Development and Globalization: Facts and Figures, Ginebra, 2006. PIB: Producto interno bruto. 


\section{III}

\section{El sindicalismo}

\section{Su papel}

Los sindicatos cumplen una multiplicidad de roles tanto en la empresa como en la sociedad. A continuación se hará referencia principalmente a su función en la negociación colectiva con la empresa. Al respecto, no faltan voces (sobre todo basadas en las teorías económicas más ortodoxas) que ven al sindicato simplemente como un monopolio real o incipiente que eleva el salario de sus miembros a expensas del empleo de los excluidos. Por cierto, no se puede negar que un sindicato, en especial uno fuerte, puede producir ese efecto. Pero esta resulta ser una visión exageradamente restrictiva del sindicalismo típico o promedio.

Es así como las teorías más sofisticadas del mercado de trabajo entienden al sindicato como una institución que perfecciona, o que puede perfeccionar, el mercado. En primer lugar, hay mercados imperfectamente competitivos, que se caracterizan por generar una renta para la empresa que rebasa la rentabilidad normal. En tales casos, será el interés de la empresa quedarse con la totalidad de la renta atribuible a su poder de mercado, pagándole a la mano de obra su costo de oportunidad (su valor en otras empresas) y no su productividad en esta. En tales situaciones, un rol crítico del sindicato será presionar a fin de conseguir parte de esas rentas para sus miembros. En estos casos, la distribución de esa renta depende del poder negociador de las partes y, dentro de amplios márgenes, no tiene efectos distorsionadores sobre la asignación de recursos. ${ }^{11}$

En segundo lugar, incluso en mercados totalmente competitivos, existe a menudo otro tipo de renta que da lugar a un margen de "legítima indeterminación" salarial. Esto se entiende mejor si partimos del análisis más ortodoxo del funcionamiento de mercados competitivos. Según este la forma de presión que caracteriza a las relaciones de mercados competitivos es conocida como "salida". Es decir, si a uno no le gusta un producto, deja de comprarlo y compra otro. Esa "salida" le manda un mensaje al productor para que mejore la calidad, el precio o ambos de su producto o perezca. De igual modo en el

\footnotetext{
${ }^{11}$ Para un interesante análisis de cómo se distribuye la renta según el poder negociador de los trabajadores en Francia, Bélgica y Chile, véase Benavente, Dobbelaere y Mairesse (2009).
}

mercado de trabajo, el disconforme con las condiciones laborales de su empresa se va de ella, presionando por medio de su "salida" para que la empresa se ponga a tono con las exigencias de la fuerza de trabajo.

No cabe duda que la salida es una importante forma de presión, mas no la única. Sobre todo en mercados con mano de obra algo calificada, donde las relaciones son más profundas y de más largo plazo, y donde los costos de salida son elevados, también cabe presionar por medio de "voz". El sindicato cumple esta función de voz. ${ }^{12} \mathrm{Y}$ la empresa es sensible a tal presión, pues sabe que el esfuerzo de su personal depende en parte importante de cuán justo considera el trato que recibe.

Hay, pues, una zona de "indeterminación legítima" en materia salarial. Si bien el mercado pone límites o rangos a cuánto se debe pagar por cierto tipo de mano de obra, salvo mercados muy excepcionales, rara vez es un monto exacto. Normalmente hay un rango de 5\% a $10 \%$ en torno de cierto valor. Este rango depende del conjunto de factores que pueden hacer que la productividad de un trabajador o de un conjunto de trabajadores sea mayor en una empresa en particular que en la generalidad de empresas. Su productividad puede ser mayor debido, por ejemplo, a que el trabajador ha adquirido conocimientos específicos del funcionamiento de su empresa; o a que se ha formado un buen espíritu de equipo con los demás, que hace que la productividad de cada uno sea mayor que lo que sería en otra empresa, entre otros factores. Hay pues un rango de "indeterminación legítimo" que corresponde a la mayor productividad que el trabajador puede tener en su empresa en relación con la generalidad de las empresas. Esta mayor productividad genera una renta que puede ser apropiada por el trabajador, por la empresa o dividida entre ambos, sin afectar mayormente al nivel de empleo. ${ }^{13}$ Esta renta es materia de negociación

\footnotetext{
${ }^{12}$ Esta teoría, originada por Hirschman (1970), ha sido aplicada muy provechosamente al mundo sindical, entre otros, por Freeman y Medoff (1984). Véanse también Pencavel (2008) y Dussaillant (2008).

${ }^{13}$ Por cierto, se puede pretender mucho más que eso, y en ese caso sí habría un efecto distorsionador, que elevaría el salario ya no solo a expensas de las rentas de la empresa, sino a costa de un menor nivel de empleo. Aquí se entiende por zona de indeterminación "legítima" esa que no distorsiona la asignación de recursos, sino que simplemente se mantiene dentro de los límites fijados por la mayor productividad específica de los trabajadores en esa empresa en relación con las demás.
} 
y "voz" es la forma más eficiente de lograrlo. De ahí uno de los papeles clave del sindicato como expresión de voz del conjunto de trabajadores.

En tercer lugar, aparte de la negociación colectiva en sí, en una empresa de tamaño mediano o grande siempre surgirán situaciones no consideradas en el contrato que requieren interpretación o nuevos acuerdos. Para el empresario obviamente es atractivo que él sea quien decida e imponga su voluntad sin discusión. Pero ello se presta para arbitrariedades y, a la larga, puede dañar las relaciones laborales afectando la moral y, por ende, la productividad. Es por eso que el sindicato cumple la función de representar los intereses de los trabajadores y de legitimar acuerdos. En la medida en que la productividad y el desempeño laboral dependan — como se sabe- no solo de cuánto es capaz de producir un trabajador, sino de cuán justo siente que es el trato que recibe, esta función legitimadora del sindicato es beneficiosa tanto para la empresa como para el trabajador.

Estos roles de distribuir rentas, negociar los rangos de "indeterminación legítima”, frenar arbitrariedades y propiciar nuevos acuerdos no anticipados, son papeles clave y positivos del sindicato, cosas muy valoradas por los trabajadores, y sobre todo en grandes empresas, valoradas también por los propios empresarios. De ahí que en las teorías modernas de recursos humanos no se consideran las relaciones laborales como esencialmente conflictivas, donde lo que gana uno es necesariamente a expensas del otro, sino que se estima que si son bien llevadas todos puedan ganar. En efecto, las condiciones laborales negociadas son vistas como justas y evocan por tanto un mayor esfuerzo por parte del trabajador que las mismas condiciones laborales, pero impuestas, en que el trabajador siente que no ha sido considerado, pues su productividad depende de su motivación y su motivación depende en parte de cómo siente que fueron tomados en cuenta sus intereses.

\section{Apreciación de los trabajadores}

Lo anterior, aun cuando pueda parecer teórico, es ampliamente corroborado por la experiencia. Por ejemplo, en una encuesta recientemente realizada por la Comisión de Equidad del Gobierno de Chile (2008) se obtuvieron los siguientes resultados: ${ }^{14}$

i. Entre el $75 \%$ y el $80 \%$ de los trabajadores considera que un sindicato es importante o muy importante

\footnotetext{
${ }^{14}$ Véase Consejo Asesor Presidencial, Trabajo y Equidad (2008). Esta comisión, designada por el gobierno, fue compuesta por "hombres buenos" de todas las tiendas políticas, académicos, empresarios y sindicalistas, y gran parte de sus conclusiones fueron unánimes.
}

para lograr un trato justo, tener más influencia en las decisiones de su empresa, obtener mejores sueldos y conseguir mayor estabilidad laboral.

ii. El $49 \%$ considera que el sindicato tiene un efecto positivo en la productividad; solo el $5 \%$ estima que su efecto es negativo.

iii. El $81 \%$ cree que sería bueno aumentar la capacidad de los trabajadores de negociar colectivamente.

iv. Si bien el $68 \%$ tiene confianza o mucha confianza en las promesas de la administración de su empresa, un porcentaje importante $-27 \%$ - tiene poca o ninguna confianza en la administración, lo que explica la necesidad de un ente como el sindicato para dar mayor confianza a lo acordado.

v. Finalmente, a diferencia de la visión ultraortodoxa en que las relaciones laborales son un juego de suma cero, el $66 \%$ de los trabajadores considera que la relación entre el sindicato y la empresa es cooperativa o muy cooperativa; solo una fracción, el $20 \%$, la considera conflictiva o muy conflictiva.

En la misma encuesta también se observa que las relaciones laborales tienden a ser mejores mientras más cercana es la autoridad, y naturalmente peores, cuando esta es más distante, lo que explicaría la mayor necesidad - si no, por otro motivo - de un sindicato en una empresa grande, donde las condiciones laborales no son fijadas por el jefe directo, sino que tienden a ser más impersonales y distantes. Por ejemplo, mientras el $82 \%$ considera buena o muy buena la relación con su jefe directo, esta apreciación positiva cae al $65 \%$ con la administración de la empresa, y al $46 \%$ con los dueños de ella.

\section{Importancia del sindicalismo}

El sindicalismo puede ser importante cuando incorpora a un alto porcentaje de la fuerza de trabajo - el caso de los países nórdicos-, así como cuando los contratos sindicales se extienden a la fuerza de trabajo no sindicalizada, como es el caso de Francia, donde - pese a su decreciente sindicalización — ha crecido la cobertura de los contratos laborales.

No obstante, cabe observar (véase el cuadro 9) que, en los últimos 25 años, en la mayoría de los países de la OCDE ha habido una caída tanto del porcentaje de trabajadores sindicalizados (una reducción del 33\%) como en la cobertura de los contratos laborales (una disminución menor, pero igualmente importante, del $22 \%$ ). Una similar tendencia declinante se observa en América Latina (véase el cuadro 10). ${ }^{15}$

\footnotetext{
${ }^{15}$ Véase Dussaillant (2008).
} 
CUADRO 9

Evolución del porcentaje sindicalizado

y del porcentaje cubierto por contrato sindical

(Selección de la OCDE)

\begin{tabular}{lcccc}
\hline \multirow{2}{*}{ País } & \multicolumn{3}{c}{ Porcentaje sindicalizado } & \multicolumn{2}{c}{$\begin{array}{c}\text { Variación porcentual en cobertura } \\
\text { de contratos sindicales (1980-2000) }\end{array}$} \\
\cline { 2 - 5 } & 1980 & 2000 & Variación porcentual & -57 \\
Reino Unido & 51 & 31 & -39 & -40 \\
Japón & 31 & 22 & -29 & -46 \\
Estados Unidos & 22 & 13 & -41 & -15 \\
Alemania & 35 & 25 & -29 & 13 \\
Francia & 18 & 10 & -44 & 13 \\
Suecia & 80 & 25 & -1 & 0 \\
Australia & 48 & 35 & -30 & 0 \\
Italia & 50 & & -33 & -22 \\
OCDE & 32 & 21 & & \\
\hline
\end{tabular}

Fuente: Organización de Cooperación y Desarrollo Económicos (OCDE), OECD Employment Outlook, París, 2004.

CUADRO 10

Evolución del porcentaje sindicalizado en América Latina

\begin{tabular}{lcrr}
\hline País & Año inicial & Año final & Variación porcentual \\
\hline Argentina & $68(1986)$ & $50(1995)$ & -26 \\
Colombia & $25(1985)$ & $18(1995)$ & -28 \\
Costa Rica & $30(1985)$ & $18(1995)$ & -40 \\
Chile & $16(1990)$ & $15(2006)$ & -7 \\
El Salvador & $10(1985)$ & $11(1995)$ & 10 \\
Guatemala & $10(1985)$ & $8(1994)$ & -20 \\
México & $42(1991)$ & $20(1997)$ & -52 \\
Panamá & $21(1991)$ & $20(1995)$ & -5 \\
Uruguay & $30(1988)$ & $21(1993)$ & -30 \\
Venezuela (Rep. Bol. de) & $29(1988)$ & $18(1993)$ & -38 \\
\hline
\end{tabular}

Fuente: Francisca Dussaillant, "Sindicatos y negociación colectiva", Documento de trabajo, № 374, Santiago de Chile, Centro de Estudios Públicos, 2008.

Este descenso en el porcentaje de trabajadores sindicalizados obedece a muchos factores. Entre otros, se pueden mencionar: ${ }^{16}$ la mayor competencia internacional debido a la globalización y, por tanto, las menores rentas monopolísticas para repartir entre empresa y trabajadores, lo que hace menos atractiva la sindicalización; los cambios tecnológicos que facilitan la descentralización y externalización de trabajos, lo que reduce el tamaño típico de las empresas (siendo las empresas de menor tamaño usualmente menos sindicalizadas); el creciente peso en la actividad económica del sector "terciario" (mucho menos sindicalizado) y el menor peso del trabajo manufacturero (por lo general altamente sindicalizado); el incremento de la importancia de los empleos profesionales

\footnotetext{
${ }^{16}$ Véase Pencavel (2008).
}

y de cuello blanco dentro de las empresas, típicamente menos sindicalizados; el aumento del empleo femenino, normalmente menos sindicalizado tanto por el tipo de labor que ellas realizan como por su participación más intermitente en la fuerza de trabajo; las políticas y prácticas antisindicales; y la deslegitimación de ciertos sindicatos debido a su falta de transparencia y democracia interna. En verdad, la única actividad en que se advierte una creciente sindicalización es la que corresponde a las labores y empresas del sector público.

\section{Efectos del sindicalismo en el empleo y la distribución del ingreso}

Como se indicó anteriormente, entre las críticas más frecuentes de la ortodoxia al sindicalismo está la que señala que el sindicato eleva los salarios de sus miembros 
a expensas del empleo. De este modo, en la medida que el sindicato impone un salario superior a lo justificado por la productividad y las condiciones del mercado (es decir, superior a la zona de legítima indeterminación), obliga a la empresa a reducir sus contrataciones, con lo que eleva el desempleo o aumenta el empleo informal. Si bien testear esta hipótesis a fondo no es materia de este trabajo, se puede avanzar algo examinando (como postula esta hipótesis): i) si países con mayor grado de sindicalización tienen un mayor nivel de desempleo (en este trabajo la muestra es de los países de la OCDE en torno del año 2000), y ii) en qué medida la reducción en el sindicalismo observada en los últimos 25 años (desde los años ochenta hasta principios de la década de 2000) ha ido acompañada de una disminución en el desempleo.

En el gráfico 4 se examina empíricamente la relación entre el porcentaje de la fuerza de trabajo sindicalizada y el desempleo en países de la oCDE alrededor del año 2000. Al contrario de la hipótesis ortodoxa convencional, no se observa la temida relación positiva entre el nivel de desempleo y el grado de sindicalización. ${ }^{17}$ Para profundizar, en el gráfico 5 se observa esta relación en el

${ }^{17}$ Resultado similar se observa si comparamos el grado de sindicalización y el desempleo en torno de 1980. Por lo tanto, la falta de significancia no se debe al período elegido. tiempo (desde 1980 a principios de la década de 2000), es decir, se examina si —como sugiere la hipótesis convencional- el desempleo cayó más en los países donde la sindicalización se retrajo más, como los Estados Unidos, el Reino Unido y el Japón, y si aumentó menos en países en que la sindicalización cayó menos, o incluso subió, como Finlandia, Islandia, Bélgica y Suecia. De nuevo, no se observa ninguna relación estadísticamente significativa entre aumentos (disminuciones) en la tasa de desempleo e incrementos (disminuciones) en la tasa de sindicalización.

Esta conclusión es corroborada en estudios más detallados de la OCDE (2004), con múltiples variables de control, donde se encuentra que entre 1970 y 2000 no hubo una relación robusta alguna entre la tasa de sindicalización y la tasa de desempleo. ${ }^{18}$ Lo poco

\footnotetext{
${ }^{18}$ En efecto, si bien, tal como sugiere la teoría convencional, la OCDE (2004) encuentra que un mayor desempleo se vincula a una mayor cobertura de negociación colectiva para algunos períodos y algunas regresiones entre 1970 y 2000 , en ninguna regresión o período es significativa la relación entre un mayor desempleo y una tasa más elevada de sindicalización. Y si bien, tal como sugiere la teoría convencional, mientras mayor es la cobertura de negociación colectiva menor es la contratación de personas de edad, al contrario de lo esperado por la ortodoxia, una mayor sindicalización se relaciona con un mayor empleo en general, y un mayor empleo femenino en particular. Dados resultados tan dispares, ambiguos y poco estables, la OCDE (2004) concluye que no hay correlación robusta entre sindicalización y desempleo.
}

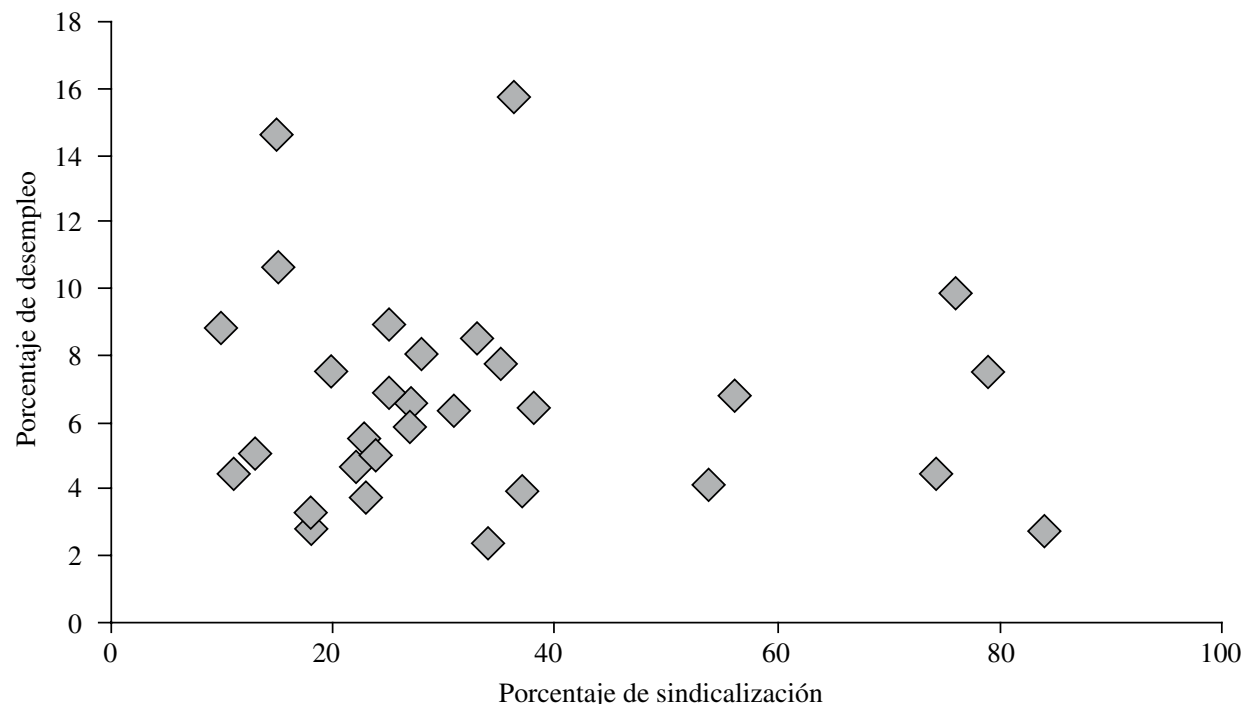

Fuente: sobre la base de datos de la Organización de Cooperación y Desarrollo Económicos (OCDE), año 2000. Nota: No hay relación estadísticamente significativa entre la tasa de desempleo y la tasa de sindicalización. 


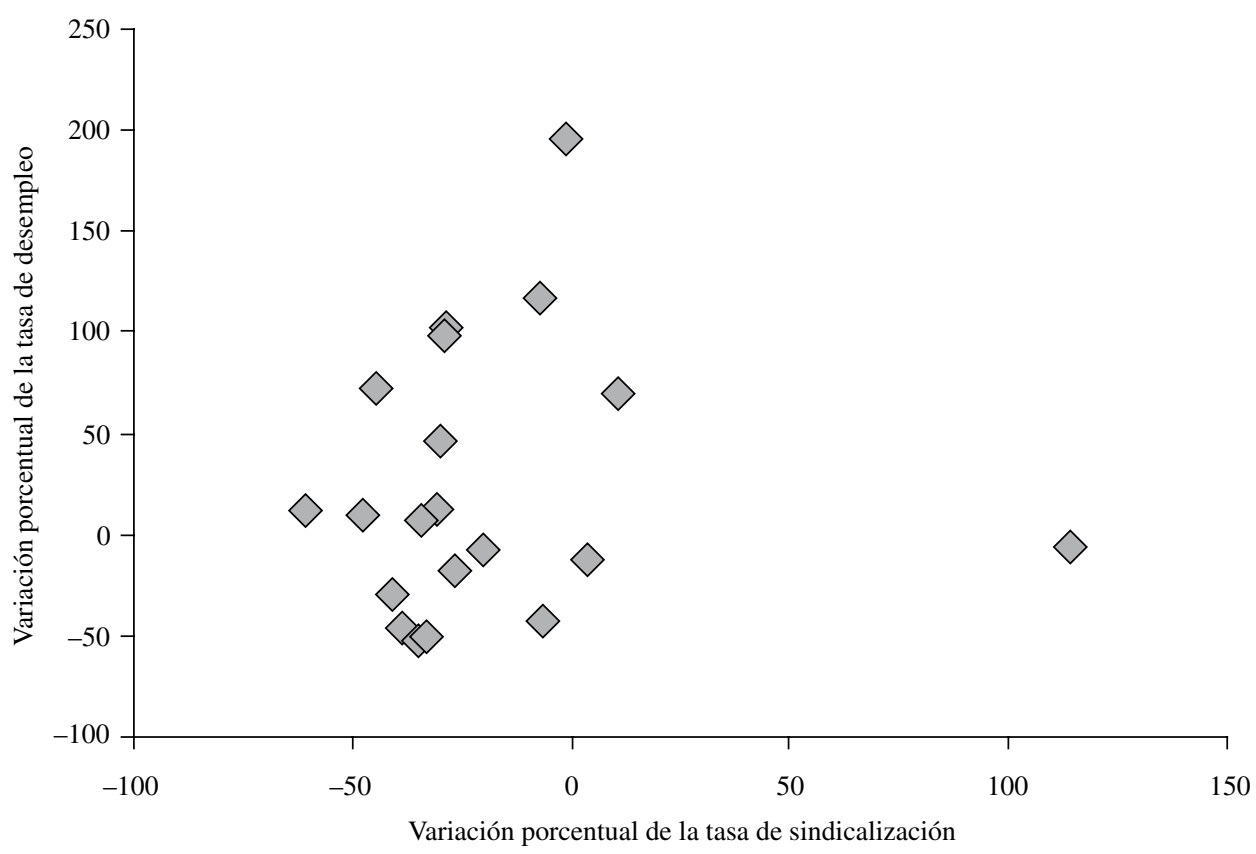

Fuente: sobre la base de datos de la Organización de Cooperación y Desarrollo Económicos (OCDE).

Nota: No hay relación estadísticamente significativa entre la variación porcentual en la tasa de desempleo y la variación porcentual en la tasa de sindicalización.

robusta o ambigua que es la relación entre desempleo y sindicalización sugiere que la interacción entre estas variables es mediada por arreglos institucionales diversos, que acentúan o incluso pueden revertir la relación convencional esperada. En cambio, la ambigüedad o falta de robustez de estos resultados sí es consistente con nuestra hipótesis de que los sindicatos elevan los salarios principalmente dentro de la zona de "legítima indeterminación", pero no suelen abusar de ello, por lo que el mayor grado de sindicalización no tiende a ser "distorsionador", es decir, no tiene un efecto significativo en el nivel de empleo.

A la inversa de la hipótesis anterior, los partidarios del sindicalismo arguyen que este, al elevar los salarios dentro de la zona de "legítima indeterminación", sobre todo los de los menos protegidos, reduce la desigualdad salarial o, al menos, ayuda a mantenerla dentro de márgenes aceptables. De ser cierta esta afirmación: i) la desigualdad salarial habría de ser menor en países de alta sindicalización (como los nórdicos) y mayor en países de baja sindicalización (como Francia, España y Estados Unidos); y ii) debería ampliarse la desigualdad salarial en los países donde la sindicalización se retrajo más
(Estados Unidos, el Reino Unido y el Japón) o mucho más que en países en que la sindicalización cayó poco o incluso aumentó.

En el gráfico 6 se relaciona el grado de sindicalización con la desigualdad salarial en torno del año 2000. Los resultados de la regresión son consistentes con esta hipótesis: mientras mayor es el grado de sindicalización, menor es el grado de desigualdad. ${ }^{19} \mathrm{Y}$ esta vez la relación es estadísticamente significativa. Por ejemplo, un país con un $20 \%$ de sindicalización tendrá una desigualdad del orden de 3,4 entre los deciles salariales mayor y menor, mientras que un país con un nivel de sindicalización del $40 \%$ tendrá una desigualdad entre deciles de 3 a 1 .

Esta hipótesis se confirma al observar la evolución de la sindicalización y la desigualdad en el tiempo. Mientras más pronunciada es la caída en la tasa de sindicalización entre 1980 y 2000, mayor es el aumento porcentual en la desigualdad salarial (véase el gráfico 7); y nuevamente

\footnotetext{
${ }^{19}$ Para una mejor comparación, se mide la desigualdad entre el decil salarial más alto y el más bajo entre hombres que trabajan a jornada completa.
} 
GRÁFICO 6 Relación entre sindicalización y desigualdad (OCDE, 2000)

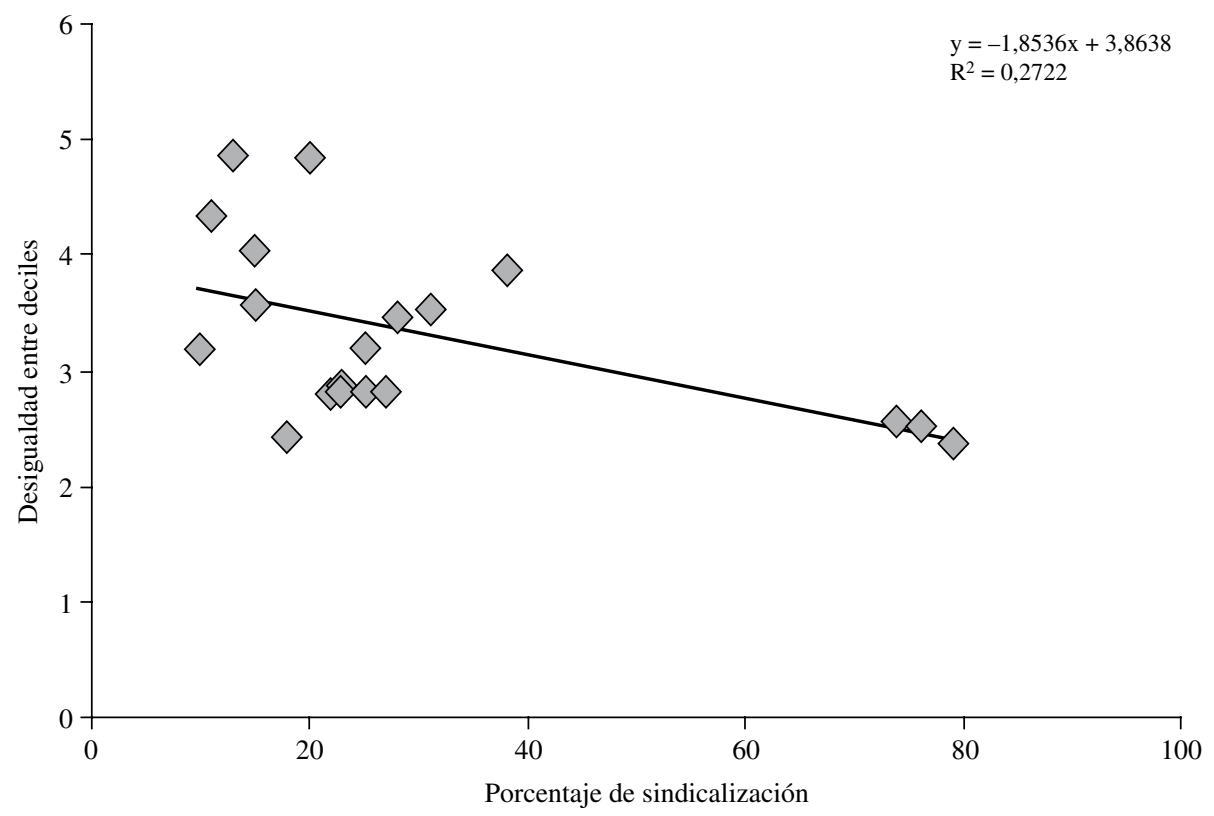

Fuente: sobre la base de datos de la Organización de Cooperación y Desarrollo Económicos (OCDE). Nota: Relación significativa al 95\% de confianza.

GRÁFICO 7

Repercusión de una menor sindicalización en la desigualdad (OCDE, años ochenta-años 2000)

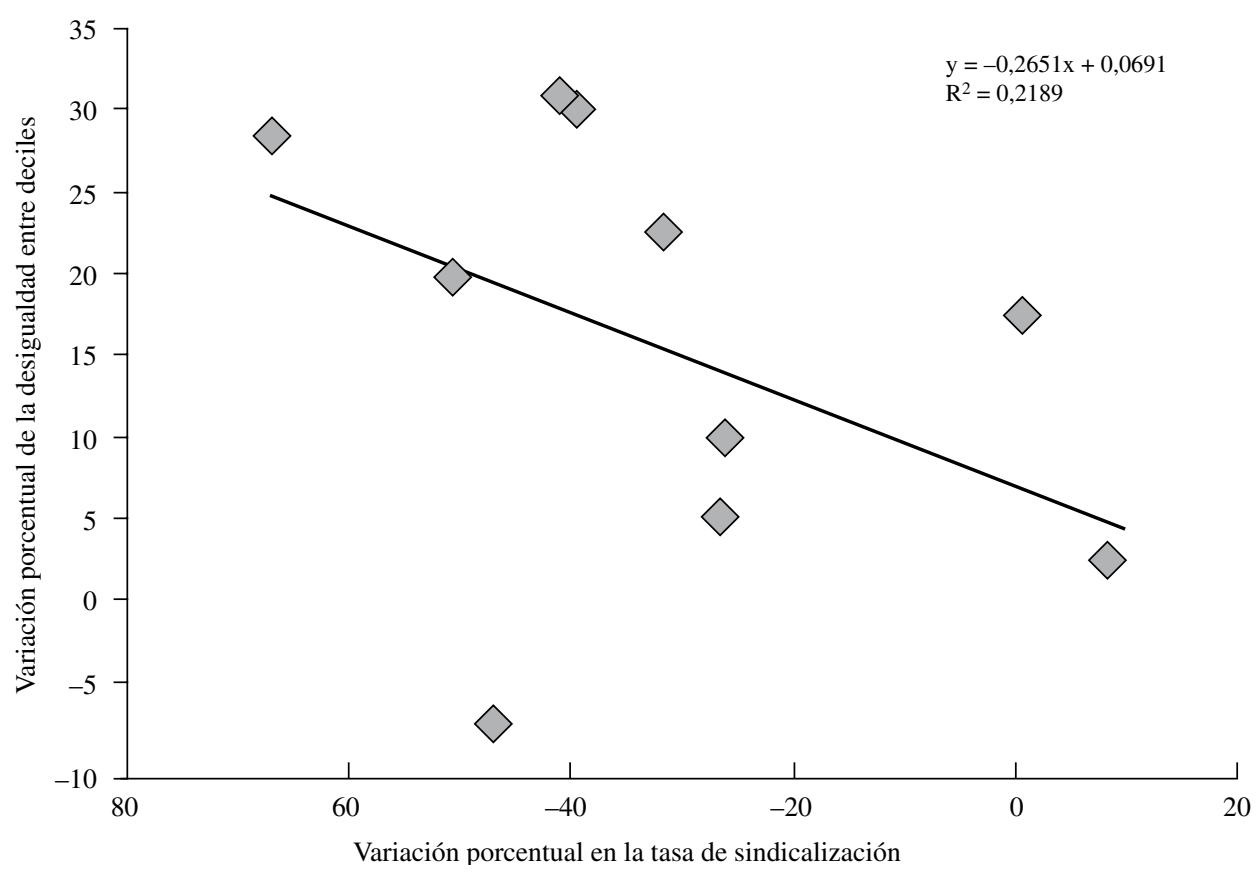

Fuente: sobre la base de datos de la Organización de Cooperación y Desarrollo Económicos (OCDE). Nota: Relación significativa al $95 \%$ de confianza. 
la relación es estadísticamente significativa. En efecto, una reducción del 33\% en el grado de sindicalización (de $32 \%$ a $21 \%$ ), como se dio en promedio en la OCDE entre 1980 y 2000 , eleva la desigualdad salarial en aproximadamente $9 \%$. Es decir, si la desigualdad entre el primer y décimo decil era de 3 a 1, con una menor sindicalización del 33\% la desigualdad entre deciles subiría a casi 3,3 a 1 . Y, a diferencia de la hipótesis anterior, la OCDE (2004) encuentra que esta relación entre mayor sindicalización y menor desigualdad salarial sí es robusta en análisis más complejos. ${ }^{20}$ Así, concluye

${ }^{20}$ Cabe señalar que la discusión sobre el efecto de los sindicatos en el empleo y la distribución de ingresos es más amplia que la arriba indicada. Entre otras cosas, hay una vasta literatura sobre el tipo de sindicalismo - si centralizado o descentralizado-y su repercusión. Al respecto, véase de nuevo OECD (2004). que la desigualdad salarial se reduce mientras mayor es la tasa de sindicalización, la cobertura de negociación colectiva o ambas, y que este resultado "concuerda con numerosos estudios anteriores (Blau y Kahn (1999); OCDE (1997) y puede ser considerado como un hecho comprobado".

Sobre la base de estos antecedentes se puede concluir que el contundente peso de la prueba recae sobre la ortodoxia, que ve en el sindicalismo una institución esencialmente negativa. En efecto, aparte de los argumentos teóricos en favor del sindicalismo (como "voz" y no solo como "salida"), la evidencia disponible con respecto a su repercusión en el empleo (no significativa) y en la equidad (significativa) sugiere que, aunque estos fueran sus únicos efectos, el sindicalismo es una institución que habría que promover antes que frenar.

\section{IV}

\section{El impacto de la globalización en los sindicatos y sus implicancias políticas}

\section{El impacto de la globalización en los sindicatos}

Antes de los años ochenta, la estrategia dominante en América Latina era la industrialización mediante sustitución de importaciones (ISI) por la vía de una férrea protección arancelaria del mercado doméstico. En países como México y Brasil, con amplios mercados nacionales, esta estrategia dio lugar a un vigoroso crecimiento económico, sin parangón en ellos, entre 1945 y 1980, por sobre un $6 \%$ anual. La estrategia fue menos exitosa en economías con mercados nacionales más reducidos $y$, por tanto, con bajos niveles de productividad, donde muchas veces el mercado nacional era insuficiente para cubrir, incluso para una sola empresa, los niveles mínimos de escala de producción eficiente. Un caso ejemplar eran las empresas automotrices argentinas y chilenas, que debido a los mercados nacionales reducidos operaban con mucha capacidad ociosa y debían cobrar un precio mucho mayor que el precio internacional del vehículo. De ahí que países como Argentina, Chile y Uruguay tuvieron ritmos de crecimiento mediocres, del orden de un 1,5\% per cápita en el período de ISI. A esta estrategia, como se sabe, se le puso fin en los años ochenta, cuando a raíz de la crisis de la deuda externa se produjo un viraje estratégico en la región, de un modelo centrado en el mercado doméstico (ISI) a un modelo de desarrollo volcado a penetrar los mercados externos.

Estas dos estrategias tienen y tenían importantes y diferentes implicancias para el desarrollo del sindicalismo en los países de la región. La estrategia de ISI, al garantizarle el mercado doméstico al productor nacional, creaba una renta monopólica para las empresas nacionales a expensas del consumidor. Esa renta pasó naturalmente a ser apetecida por el sindicato, pues no era el resultado de ningún esfuerzo o productividad mayor de la empresa, sino que era fruto de la protección otorgada por la autoridad política. Era un claro caso de juego de suma cero entre capital y trabajo, que obviamente daba lugar a relaciones esencialmente conflictivas.

$\mathrm{Al}$ abrirse las economías, la competencia externa redujo drásticamente o incluso hizo desaparecer la renta monopólica, llegando en algunos casos a cerrarse la empresa, y en general reduciendo ostensiblemente las ganancias. Al desparecer las rentas monopólicas, la suerte del empresario así como la de los trabajadores 
pasó a depender del éxito de la empresa, como un todo, al competir con el exterior. Las utilidades, de haberlas, ya no eran espurias, fruto de un acto de la autoridad, sino reales, resultado del esfuerzo del conjunto por mejorar la productividad y competir. Como el aumento en la productividad es el resultado de la cooperación entre capital y trabajo, las relaciones laborales pasan a ser más cooperadoras entre las partes, mientras que el principal "conflicto" es lograr competir en el exterior. Sin embargo, y como se señaló anteriormente, la cooperación entre las partes le genera a la empresa una renta específica que da lugar a una zona de "indeterminación salarial legítima”, que sí requiere de la negociación de las partes para determinar su repartición.

\section{Implicancias políticas para el sindicalismo}

¿Qué campos de negociación adquieren mayor importancia para los sindicatos en este nuevo escenario de globalización? Se distinguirá entre los campos que adquieren mayor relieve fuera de la empresa (primero en el plano internacional, luego en el nacional) y los que lo hacen dentro de la empresa.

\section{a) Fuera de la empresa, en el plano internacional}

Mientras que durante la estrategia de IsI lo central era el plano nacional y el de la empresa, con la globalización surgen temas que desbordan estos niveles y relevan el plano internacional. Muy en particular es tema para la discusión internacional todo lo concerniente a las asimetrías observadas en el actual proceso de globalización. Esta ha de significar el mayor flujo de todos los factores de producción, no solo de bienes y capital, sino también de tecnología y mano de obra.

Hasta ahora, al parecer, ha sido un axioma no cuestionado de la globalización el promover el más libre flujo de bienes y de capital, pero sin decir lo mismo, por ejemplo, sobre los flujos migratorios. Hace falta considerar este tema, no como hasta ahora como prerrogativa exclusivamente nacional — del país receptor de migrantes-, sino como contrapartida natural del mayor flujo de todos los factores de producción. Si bien en el Informe sobre desarrollo humano 2009 se reivindica esta postura en nombre de la comunidad internacional, esta posición debería ser reforzada por el sindicalismo del Sur. En efecto, la mejora de los ingresos de los trabajadores en los países de la región pasa por reducir la actual abundancia relativa de mano de obra poco calificada. Y ¿existe una manera más rápida de reducir esta abundancia que promover una mayor migración de mano de obra poco calificada a los países desarrollados (donde se necesita mucha mano de obra de baja calificación en tareas cada vez más demandadas, como el cuidado de enfermos y de personas de la tercera edad)? Así como un flujo relativamente libre de mano de obra fue importante para el desarrollo de Europa en el siglo XIX y tal como la libertad de movimiento laboral es hoy relevante para la Unión Europea y las nuevas economías del Este que se han vinculado a ella, del mismo modo un mayor flujo de migrantes al Norte puede ser un importante componente de la mejora en las condiciones laborales de las masas del Sur. Por cierto, la emigración no sustituye mejores estrategias nacionales de desarrollo, pero sí es un complemento relevante, por lo que debería contar con un decidido respaldo del sindicalismo del Sur, que procuraría, por solidaridad, el apoyo del sindicalismo del Norte.

No es que necesariamente se condicione el mayor flujo de capitales al mayor flujo de migración (puesto que puede ser aún peor para los países en desarrollo tener menos IED, así como pocas posibilidades de migrar). Pero debe insistirse en que la globalización implica el mayor flujo de factores de producción entre países, y en el límite, la libre entrada de todos los factores de producción, tanto de mano de obra como de capital. De modo que hay que apuntar hacia un mucho mayor flujo de mano de obra (condicionado, a lo sumo, a mantener en pie la cultura del país receptor). Mas no solo una mayor migración, sino sobre todo de mano de obra menos calificada, en vivo contraste con la actualidad en que los países receptores aceptan, o incluso atraen, mano de obra calificada y profesional, pero rehúyen o rechazan la menos calificada. $Y$ de nuevo lo hacen como si fuera un tema exclusivamente de incumbencia nacional, cuando - por contraste — en lo que se refiere al intercambio de bienes y flujos de capital se considera que han de primar los intereses internacionales sobre los meramente nacionales. Obviamente, no será fácil revertir la situación actual, por lo que es central crear conciencia de que el libre flujo de mano de obra del Sur al Norte es la contrapartida natural al libre flujo de capitales en dirección contraria. Y en esto el sindicalismo tiene un importante papel que jugar tanto en el Norte como en el Sur.

La contrapartida de esta defensa de la libre migración es el fortalecimiento de normas laborales tanto en los países de destino como en los de origen. Los países receptores que aún no han ratificado las convenciones internacionales que protegen a los trabajadores migrantes han de hacerlo. En todo caso, y tal como recomienda el Informe sobre desarrollo humano 2009, los países deberían asegurar que los migrantes tengan derechos 
laborales plenos e igual pago para igual trabajo; dispongan de condiciones laborales decentes y seguras; puedan organizarse colectivamente; y gocen de derechos plenos a la educación y al estudio del idioma del país de destino para sus hijos. Además, tanto los países de origen como los de destino deberían colaborar en facilitar el reconocimiento de competencias educacionales y laborales obtenidas en el país de origen.

\section{b) Fuera de la empresa, en el plano nacional}

Primero, en un mundo globalizado va a ser cada vez más importante defender los derechos laborales básicos, no solo en la letra (convenciones) sino en la práctica. Es importante en sí y es relevante si se pretende que los países de la región tengan acceso a los mercados internacionales, pues va a ser cada vez más inaceptable importar desde países sin normas o que hacen caso omiso de ellas. Un papel importante del sindicalismo será procurar que en las normas nacionales se acojan los principios internacionales expresados en los distintos convenios y recomendaciones de la Organización Internacional del Trabajo (OIT).

Desde luego, estas normas no pueden ser idénticas en sus detalles a las de los países desarrollados, sino que deben acoger los mismos principios, pero ajustados a las diferencias en niveles de desarrollo. Deben comprender cláusulas similares, con miras a converger en la medida que se acerquen los niveles de desarrollo. Si bien las definiciones precisas han de variar según su nivel de desarrollo, todo país deberá poner límites estrictos, si no prohibiciones, al trabajo infantil; límites a la jornada laboral regular; considerar un salario o ingreso mínimo; implementar una protección del sindicalismo y promover la negociación colectiva, y establecer normas de seguridad e higiene mínima en el trabajo, entre otras medidas.

Segundo, en un mundo globalizado, donde las economías están cada vez más interrelacionadas y, por tanto, sujetas a los vaivenes de la economía internacional, será necesario diseñar políticas que defiendan al trabajador de recesiones producto de impactos (shocks) externos. Obviamente, la primera defensa del empleo es una buena política macroeconómica. De ahí que sea indispensable que el sindicalismo insista y presione en pos de políticas contracíclicas con el mayor número de "estabilizadores automáticos".

Entre los más relevantes de dichos estabilizadores están el abogar por políticas fiscales que varíen automáticamente con el ciclo económico, es decir, que impliquen ahorrar en tiempos de bonanza para permitir déficits en tiempos de baja. La política de equilibrio estructural chilena es ejemplar al respecto. En ella el presupuesto público se diseña para gastar no según los ingresos fiscales del momento, sino de acuerdo con los ingresos que se obtendrían si la economía siguiera creciendo al ritmo de su tendencia y con un precio del cobre (exportación crítica) a su valor de largo plazo. Ello significa que en períodos de auge, con un alto precio del cobre, el fisco ahorra y genera superávit, para de ese modo poder gastar más de lo que ingresa en períodos de baja, cuando la economía está creciendo menos que su potencial y el precio del cobre está por debajo de su valor de más largo plazo. Esta política da lugar a un gasto público neutro al ciclo, en lugar de lo que actualmente ocurre en muchos países, donde el gasto público acentúa el ciclo. Tal política fue responsable de que la actual crisis internacional tuviera un impacto recesivo menor en Chile y con menos secuelas que la crisis asiática.

Una tercera línea es abogar por el diseño de políticas que, cuando no haya podido evitarse una recesión, induzcan a minimizar los despidos. De hecho, en situaciones recesivas, cuando las ventas y, por ende, la producción caen, se hacen necesarios recortes en el empleo. Se propone que el sindicalismo promueva que, en tales situaciones, la autoridad induzca a las empresas a reducir la jornada laboral, digamos en un $10 \%$, antes que despedir al $10 \%$ de su personal. ${ }^{21}$ Por duro que sea, todos pueden ajustarse a recibir un $10 \%$ menos de ingreso. Sin embargo, nadie puede ajustarse a perder el $100 \%$ de su ingreso, como es el caso del que queda cesante. Por consiguiente, en situaciones declaradas como recesivas por la autoridad competente, es socialmente preferible que las empresas disminuyan sus requerimientos de mano de obra por medio de reducciones generales en la jornada de trabajo, antes que por medio de despidos. Llama la atención que varios países de la oCDE han adoptado medidas de esta naturaleza durante la crisis internacional reciente, por lo que pese a haber sufrido una recesión más severa que los Estados Unidos, por ejemplo, Alemania ha registrado un incremento del

\footnotetext{
${ }^{21}$ Esto se puede inducir simplemente permitiendo que, en situaciones declaradas como recesivas por una autoridad competente, se autorice a las empresas a reducir unilateralmente las horas de trabajo (y la remuneración en forma proporcional), sin que esto sea una violación del contrato laboral; y permitiendo que el trabajador que no considere esto justo, se retire voluntariamente de la empresa con la indemnización correspondiente por despido. Es de suponer que en tales situaciones, cuando gran parte de las empresas están despidiendo personal, la inmensa mayoría de los trabajadores preferirán un $10 \%$ menos de horas laborales que el despido del $10 \%$ del personal. Por cierto, esto se puede inducir en forma más enérgica si, además, el gobierno subsidia parcialmente la reducción de horas (por ejemplo, en un 50\%), permitiendo que el trabajador absorba en su ingreso apenas la mitad de la reducción en horas.
} 
desempleo mucho menor que el de ese país. Promover una legislación que autorice la reducción de horas laborales en lugar de despidos es, pues, otro desafío importante para el sindicalismo en el plano nacional.

Cuarto, el sindicalismo ha de propugnar el establecimiento de seguros de cesantía. Estos no son un lujo de los países desarrollados, sino una necesidad para cualquier país sujeto a crisis económicas en un mundo globalizado. Lógicamente, los montos dependerán del nivel de desarrollo, del nivel de empleo formal y de la factibilidad de administración. Pero un seguro de cesantía es un instrumento crítico para el sindicalismo porque, por una parte, defiende los ingresos (amortigua la pérdida) de los que más lo necesitan, los cesantes. Por otra, al estabilizar los ingresos de los cesantes, aminora la presión a la baja en los ingresos de los ocupados.

Quinto, el empleo productivo depende en forma crucial de la preparación y capacitación de la mano de obra. De ahí que reivindicación clave del sindicalismo radica en presionar para que cada joven que ingrese a la fuerza de trabajo tenga un oficio serio; que no se incorpore carente de oficio, como es el caso de la mayoría de los que ingresan al mercado laboral habiendo egresado, o desertado, de la enseñanza media. Asimismo, lograr mejoras continuas en productividad requiere de una fuerza de trabajo en continua superación. Por ello es importante reivindicar el derecho de todo trabajador a tener la seguridad de poder seguir capacitándose en forma regular durante su vida laboral.

Por una parte, esto significa abogar para que cada joven que abandone la enseñanza secundaria o que egrese de ella, pero no ingrese a la etapa superior, tenga un crédito que le permita recibir una enseñanza técnica superior de calidad (generalmente de dos años). Es evidente que un joven sin un oficio serio está condenado a una labor de escasa productividad durante toda su vida laboral. Garantizarle la posibilidad de adquirir un oficio serio implica que recibirá un ingreso que lo ubicará en la clase media del país (lo que reducirá las peores desigualdades características de los países en desarrollo) y le permitirá ascender durante su vida profesional. El costo de tal medida es factible para la mayoría de los países en desarrollo, al menos de nivel medio, y su alta rentabilidad implica que se pagará con creces. ${ }^{22}$

\footnotetext{
22 Se estima que el costo de una buena educación técnica, de nivel superior, es del orden de los 4.000 dólares (2.000 dólares por año, por dos años) en un país de desarrollo intermedio, como Chile. Si las dos terceras partes de los jóvenes no ingresaran a la educación superior, (para un país con un PIB per cápita, en paridad de poder adquisitivo (PPA), de 10.000 dólares) ello implicaría un costo del orden de $1 / 2 \%$ del PIB si fuera un crédito no reembolsable, es decir, una pura beca; y,
}

Por otra parte, debe abogarse para garantizar que cada trabajador tenga derecho a seguir cursos de capacitación el uno por ciento de su vida laboral (lo que significa recibir capacitación por cinco meses a lo largo de una vida laboral de 45 años en lugar de uno o dos meses que suele recibir el trabajador medio en la región). Ello con miras a acelerar el aumento en la productividad y, por ende, en los salarios de los trabajadores a lo largo de su vida profesional. La única condición sería que la capacitación se impartiera en una institución cuya calidad fuera acreditada y preferentemente en áreas y trabajos considerados prioritarios por la autoridad.

Sexto, convendría reconsiderar las políticas de salario mínimo (cuyo costo absorbe la empresa) y ver si no es preferible que el sindicalismo abogue por asegurar un ingreso mínimo (cuyo costo lo absorbe, al menos en parte, el fisco). En economías cerradas, el costo de un mayor salario mínimo podía ser traspasado al consumidor sin mayor gasto por parte de la empresa, con lo que el efecto sobre el desempleo de un mayor salario mínimo era bajo. En cambio, en economías abiertas, el mayor salario mínimo no puede ser traspasado al consumidor, por lo que la empresa debe absorber los aumentos en el mínimo no compensados por mejoras en productividad; de ahí que incrementos considerados necesarios desde el punto de vista social podrían tener consecuencias potencialmente negativas para el empleo.

Se puede lograr un ingreso mínimo superior al salario mínimo sin consecuencias negativas para el empleo si la diferencia entre el salario ganado y el ingreso mínimo considerado como mínimamente aceptable es absorbido por el fisco bajo la forma de un subsidio al trabajador de ingresos bajos en lugar de absorberlo la empresa. En este caso el trabajador recibe el ingreso considerado mínimamente aceptable, pero el costo no sube para la empresa, de modo que no se incentiva la no contratación. Desde luego, esto implica un costo fiscal que será absorbido por toda la sociedad, o por todas las empresas. Pero como se trata de un costo que es independiente del nivel de contratación, no la desincentiva, como sí puede hacerlo el salario mínimo.

\section{c) Dentro de la empresa}

Por cierto, es función clásica del sindicalismo y lo seguirá siendo en el futuro negociar las condiciones laborales más idóneas dentro de la llamada zona de "legítima indeterminación" salarial. Tal como se explicó

obviamente, sería mucho menor, si se tratara de un crédito parcialmente reembolsable según cuán alta fue su categoría de graduación (lo que estimularía que todos se esforzaran más por aprender el oficio). 
anteriormente, esta zona corresponde a ese 5\% o $10 \%$ más (o menos) en que la productividad específica del conjunto de trabajadores en una empresa particular pudiera diferir de la productividad individual de esos trabajadores en otras empresas.

Además de esta función, en economías más abiertas, producto de la globalización, se hace más necesario e interesante buscar formas de negociación que ayuden a competir con el exterior y colaborar hacia dentro. Entre las propuestas más interesantes en este ámbito está la de negociar "salarios participativos". ${ }^{23} \mathrm{El}$ sistema salarial actual tiende a operar sobre la base de un sueldo fijo por un tiempo determinado. En consecuencia, en situaciones recesivas, la empresa tiene un incentivo para despedir, pues no puede bajar sus costos porque tiene que cumplir con el sueldo fijo convenido. En cambio, en la medida en que una parte importante del ingreso del trabajador fuera variable (un porcentaje acordado de las ventas, o del valor de producción, o del valor agregado de la empresa, o de las utilidades), en situaciones recesivas la empresa será más propensa a bajar su precio, ya que en alguna medida también caerá el componente variable del salario, por lo que tenderá a mantener su producción y el empleo. Inversamente, en situaciones de auge, aumenta automáticamente el componente variable del ingreso del trabajador, por lo que participa en el buen momento económico de la empresa.

Es por eso que los salarios participativos tienen esta atractiva propiedad de minimizar la caída en la producción, así como del empleo, en situaciones difíciles, y de mejorar (respecto de lo que habría sido) la distribución del ingreso en períodos de auge. Esto no es pura teoría. ${ }^{24}$ El Japón se caracteriza por pagar salarios

\footnotetext{
${ }^{23}$ Esta política, que se describe en seguida, ha sido propuesta y popularizada por Weitzman (1984).

${ }^{24}$ Véanse Weitzman y Kruse (1989). Marinakis (1999) hace un interesante análisis de los problemas operacionales con distintos sistemas de participación en los resultados en América Latina. Concluye que
}

participativos, con un componente variable del orden del $25 \%$ del ingreso total. En consecuencia, pese a la recesión y largo estancamiento de fines de los años noventa, el desempleo japonés nunca superó el 5,5\%.

Una virtud adicional de los salarios participativos es que, al ligar más estrechamente los ingresos del conjunto de trabajadores con el desempeño de la empresa, se induce a un mayor esfuerzo y al mejoramiento en la productividad. De tal modo que esta forma de remuneración promueve una mayor colaboración dentro de la empresa y es una mejor defensa ante los vaivenes de la economía internacional. En una publicación reciente se concluye que "un sistema de remuneraciones de este tipo [de salarios participativos], bien pensado, bien explicado y llevado adelante en forma honesta y transparente es, sin lugar a dudas, una de las más poderosas herramientas de gestión que puede disponer toda empresa Pyme" (Berg, 2007).

Si bien ha habido cierta reticencia a su adopción, ${ }^{25}$ se ha tendido a aplicar estas formas de remuneración. Por consiguiente, es razonable proponer que los sindicatos vayan presionando para que los futuros incrementos en sus ingresos se den por esta vía más que exclusivamente mediante aumentos en los sueldos fijos.

\footnotetext{
cuando estos sistemas son producto de la negociación colectiva y no impuestos por ley, representan un instrumento importante para mejorar tanto las relaciones laborales como la competitividad.

${ }^{25}$ Por una parte, los trabajadores tienen una aversión al riesgo, lo que les hace preferir salarios fijos en vez de variables. No obstante, ello no reduce el riesgo sino que cambia un tipo de riesgo por otro. En efecto, un salario fijo tiene un mayor riesgo de desempleo, por lo que los salarios participativos dan lugar a mayores fluctuaciones en los ingresos a cambio de un menor riesgo de desempleo. Por otra parte, hay desconfianza en ligar el componente variable a utilidades, ya que estas son tan fáciles de "maquillar". Por lo tanto, es importante ligar el componente variable a algún parámetro relacionado con utilidades, pero más fácil de verificar, como son el nivel de ventas o de producción.
} 


\section{V}

\section{Conclusión}

Más allá de vaivenes momentáneos que pueden aminorar la globalización (por ejemplo, la reciente crisis internacional) o acelerarla, parece evidente que ella llegó para quedarse. Por lo demás, es probable que la tendencia a largo plazo sea a acentuar esta integración de las economías del mundo. Pero es importante que se vaya reduciendo la actual asimetría.

Si bien hasta ahora el comercio internacional lleva por mucho la delantera, para el sindicalismo del Sur es importante que aumenten bastante más los flujos de capital entre los países, así como la transferencia tecnológica, pues son esenciales para elevar los bajos niveles de productividad del Sur y, por ende, para ofrecer la oportunidad de trabajos con ingresos decentes. En lo que se refiere a la oferta de trabajo, es en los bajos flujos migratorios actuales donde más flaquea la globalización. Como sugiere el Informe sobre desarrollo humano 2009, ampliar estos flujos en forma significativa, sobre todo de mano de obra no calificada, sería decisivo para poder aliviar la abundancia de mano de obra en el Sur, abundancia relativa que, salvo contados casos (las mineras y el sector público), inhibe considerablemente el poder de negociación del sindicalismo del Sur.

Sin embargo, la globalización no solo afecta al sindicalismo, sino que le brinda nuevas oportunidades de actuar, algunas de las cuales se han resaltado en este artículo. El sindicalismo tiene una larga historia y, con más o menos globalización, seguirá jugando un papel importante en el futuro, sobre todo si potencia roles como los indicados, que adquieren mayor relieve con la globalización.

\section{Bibliografía}

Álvarez, Roberto, Gustavo Crespi y Joseph Ramos (2002), "The impact of licenses on a "late starter" LDC: Chile in the 1990s", World Development, vol. 30, $\mathrm{N}^{\circ} 8$, Amsterdam, Elsevier, agosto.

Banco Mundial (2009), Informe sobre el desarrollo mundial 2009, Washington, D.C.

Benavente, José Miguel, Sabien Dobbelaere y Jacques Mairesse (2009), "Interaction between product market and labour market power: evidence from France, Belgium and Chile", Applied Economics Letters, vol. 16, $\mathrm{N}^{\circ}$ 6, Londres, Routledge, abril.

Berg, Hubert (2007), Salarios participativos: una herramienta para el compromiso, Santiago de Chile, Organización Internacional del Trabajo (OIT).

Bhagwati, Jagdish (2004), In Defense of Globalization, Nueva York, Oxford University Press.

Blau, Francine y Lawrence Kahn (1999), "Institutions and laws in the labor market", Handbook of Labor Economics, O. Ashenfelter y D. Card (comps.), vol. 3, Amsterdam, North Holland.

Brown, Drusilla, Alan Deardorff y Robert Stern (2003), "The effects of multinational production on wages and working conditions in developing countries", NBER Working Paper, $\mathrm{N}^{\circ}$ 9669, Cambridge, Massachusetts, National Bureau of Economic Research.

Castaldi, Carolina y otros (2009), "Technological learning, policy regimes, and growth: the long term patterns and some specificities of a globalized economy", Industrial Policy and Development, Mario Cimoli, Giovanni Dosi y Joseph Stiglitz, Nueva York, Oxford University Press.

CEPAL (Comisión Económica para América Latina y el Caribe) (2008), La inversión extranjera directa en América Latina y el Caribe, 2008 (LC/G.2406-P), Santiago de Chile. Publicación de las Naciones Unidas, $\mathrm{N}^{\circ}$ de venta: S.09.II.G.24.

Consejo Asesor Presidencial, Trabajo y Equidad (2008), Encuesta: percepciones sobre relaciones laborales y equidad, Santiago de Chile, agosto.
Dussaillant, Francisca (2008), "Sindicatos y negociación colectiva", Documento de trabajo, $\mathrm{N}^{\circ} 374$, Santiago de Chile, Centro de Estudios Públicos.

Freeman, Richard y James Medoff (1984), What Do Unions Do, Nueva York, Basic Books.

Gray, John (1998), False Dawn: The Delusions of Global Capitalism, Nueva York, New Press.

Hirschman, Albert (1970), Exit, Voice and Loyalty, Cambridge, Harvard University Press.

Maddison, Angus (2001), The World Economy: A Millennial Perspective, París, Organización de Cooperación y Desarrollo Económicos (OCDE).

Marinakis, Andrés (1999), "Participación de los trabajadores en las utilidades o resultados de las empresas en América Latina", Revista de la CEPAL, No 69 (LC/G.2067-P), Santiago de Chile, diciembre.

Micklethwait, John y Adrian Wooldridge (2000), A Future Perfect: The Hidden Promise of Globalization, Nueva York, Times Books.

Naciones Unidas (2009), Informe sobre desarrollo humano 2009. Superando barreras: movilidad y desarrollo humanos, Nueva York. (2006), International Migration Report 2006: A Global Assessment (ESA/P/WP.209), Nueva York.

oCDE (Organización de Cooperación y Desarrollo Económicos) (2004), "Wage-setting institutions and outcomes", OECD Employment Outlook, París. (1997), OECD Employment Outlook, París.

OMC (Organización Mundial del Comercio) (2008), Perfiles arancelarios en el mundo 2008, Ginebra.

Pencavel, John (2008), "Una mirada internacional al sindicalismo", Estudios públicos, $\mathrm{N}^{\circ} 110$, Santiago de Chile, Centro de Estudios Públicos.

Stiglitz, Joseph (2003), Globalization and its Discontents, Nueva York, Norton. 
The Economist (2009), "Migration and development: the aid workers who really help", 10 de octubre de 2009.

UNCTAD (Conferencia de las Naciones Unidas sobre Comercio y Desarrollo) (2008), Informe sobre las inversiones en el mundo, 2008 (UNCTAD/wIR/2008), Nueva York, 2008. Publicación de las Naciones Unidas, $\mathrm{N}^{\mathrm{o}}$ de venta: E.08.II.D.3.

(2006), Development and Globalization: Facts and Figures, Ginebra.
Visser, Jelle (2006), "Union membership statistics in 24 countries", Monthly Labor Review, vol. 129, No 1, Washington, D.C., Bureau of Labor Statistics, enero.

Weitzman, Martin (1984), The Share Economy, Cambridge, Harvard University Press.

Weitzman, Martin y Douglas Kruse (1989), "Profit sharing and productivity", Paying for Productivity, Alan Blinder (comp.), Washington, D.C., The Brookings Institution. 